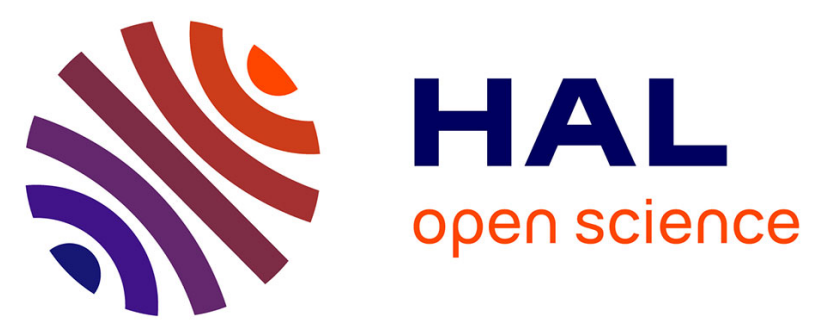

\title{
Design of Boron Nitride/Gelatin Electrospun Nanofibers for Bone Tissue Engineering
}

Sakthivel Nagarajan, Habib Belaïd, Céline Pochat-Bohatier, Catherine Teyssier, Igor Iatsunskyi, Emerson Coy, Sébastien Balme, David Cornu, Philippe Miele, Narayana S. Kalkura, et al.

\section{To cite this version:}

Sakthivel Nagarajan, Habib Belaïd, Céline Pochat-Bohatier, Catherine Teyssier, Igor Iatsunskyi, et al.. Design of Boron Nitride/Gelatin Electrospun Nanofibers for Bone Tissue Engineering. ACS Applied Materials \& Interfaces, 2017, 9 (39), pp.33695 - 33706. 10.1021/acsami.7b13199 . hal-01659508

\section{HAL Id: hal-01659508 \\ https://hal.umontpellier.fr/hal-01659508}

Submitted on 9 Jun 2021

HAL is a multi-disciplinary open access archive for the deposit and dissemination of scientific research documents, whether they are published or not. The documents may come from teaching and research institutions in France or abroad, or from public or private research centers.
L'archive ouverte pluridisciplinaire HAL, est destinée au dépôt et à la diffusion de documents scientifiques de niveau recherche, publiés ou non, émanant des établissements d'enseignement et de recherche français ou étrangers, des laboratoires publics ou privés. 


\section{Design of Boron Nitride/Gelatin Electrospun Nanofibers for Bone}

\section{Tissue Engineering}

Sakthivel Nagarajan ${ }^{1,2}$, Habib Belaid ${ }^{1,3}$, Céline Pochat-Bohatier ${ }^{1}$, Catherine Teyssier ${ }^{3}$, Igor Iatsunskyi ${ }^{4}$,Emerson Coy $^{4}$, Sébastien Balme ${ }^{1}$, David Cornu ${ }^{1}$, Philippe Miele ${ }^{1}$, Narayana S. Kalkura $^{2}$, Vincent Cavaillès ${ }^{3 *}$ and Mikhael Bechelany ${ }^{1 *}$

${ }^{1}$ Institut Européen des Membranes, UMR 5635, Université Montpellier, CNRS, ENSCM, Place Eugene Bataillon, F-34095 Montpellier cedex 5, France

${ }^{2}$ Crystal Growth Centre, Anna University, Chennai, India, 600025.

${ }^{3}$ IRCM, Institut de Recherche en Cancérologie de Montpellier, INSERM U1194, Université Montpellier, Montpellier F-34298, France

${ }^{4}$ NanoBioMedical Centre, Adam Mickiewicz University, 85 Umultowska str., 61-614, Poznan, Poland

* Corresponding authors:

mikhael.bechelany@ umontpellier.fr, Phone: +33467149167, Fax: +33467149119

vincent.cavailles@inserm.fr, Phone: +33467612405, Fax: +33467613787

\section{KEYWORDS}

Gelatin, boron nitride, nanosheets, bionanocomposites, electrospinning, mechanical properties, tissue engineering 


\section{ABSTRACT}

Gelatin is a biodegradable biopolymer obtained by collagen denaturation, which shows poor mechanical properties. Hence, improving its mechanical properties is very essential towards the fabrication of efficient nontoxic material for biomedical applications. For this aim, various methods are employed using external fillers such as ceramics or bioglass. In this report, we introduce boron nitride $(\mathrm{BN})$ reinforced gelatin as a new class of two dimensional biocompatible nanomaterials. The effect of the nanofiller on the mechanical behavior is analyzed. BN is efficiently exfoliated using the biopolymer gelatin as shown through Fourier transform infrared (FTIR) spectroscopy and X-ray diffraction (XRD). The exfoliated BN reinforces gelatin electrospun fibers, which results in an increase in the Young's modulus. The ESM are stable after the glutaraldehyde cross-linking and the fibrous morphology is preserved. The cross-linked gelatin/BN ESM is highly bioactive in forming bone like hydroxyapatite as shown by scanning electron microscopy. Due to their enhanced mineralization ability, the cross-linked ESM have been tested on human bone cells (HOS osteosarcoma cell line). The cell attachment, proliferation and biocompatibility results show that the ESM are nontoxic and biodegradable. The analysis of osteoblast gene expression and the measurement of alkaline phosphatase activity confirm that these materials are suitable for bone tissue engineering. 


\section{INTRODUCTION}

Gelatin is denatured collagen, extracted from acidic (Type A) or basic (Type B) treatment of bovine or porcine skin, bone or tendons. Gelatin found broad applications in food and pharmaceutical industry as thickening agent, stabilizer, protective coating material, or in emulsion preparation for ointments and $\operatorname{cosmetics}^{1-2}$. The degradable biopolymer gelatin is also used as biomaterial in cardiovascular grafts ${ }^{3-4}$, drug delivery vehicles ${ }^{5}$ and scaffolds to form cartilage like extracellular matrix ${ }^{6}$. The hemostatic property of gelatin has attracted interest in surgery as a wound dressing materials and adsorbent pads ${ }^{7-8}$. Gelatin is also studied to be used as a bone grafting material ${ }^{9}$. Zha et al. and Lee et al. reported that osteoblast cells attach more prominently and proliferate on the surface of gelatin fibers ${ }^{10-11}$. Gelatin possesses poor bioactivity which is improved by the addition of hydroxyapatite or bioglasses ${ }^{12-14}$. However, addition of bioactive hydroxyapatite to the gelatin electrospun does not significantly improve the mechanical properties of the nanofibers ${ }^{15-17}$. Hence, synthesizing new class of biocompatible and bioactive material is essential for the fabrication of biomaterials which allow osteoblast proliferation for orthopedic implant applications.

Hexagonal boron nitride is an isoelectronic analogue of graphite which displays numerous interesting properties ${ }^{18}$. It will be denoted as $\mathrm{BN}$ in the following sections, the hexagonal polymorph susceptible to lead to BN sheets by exfoliation being the subject of this paper. The exfoliated single layers of graphene found wide applications due to their high mechanical strength ${ }^{19}$. Hence, preparing composites using exfoliated $\mathrm{BN}$ will be a new approach to improve mechanical properties of gelatin biopolymers ${ }^{20}$. Monolayer of $\mathrm{BN}$ is prepared using top down ${ }^{21-22}$ and bottom up ${ }^{23-24}$ approach methods. The exfoliation of BN can be achieved through polar-polar interaction with $\mathrm{N}, \mathrm{N}$ dimethyl formamide ${ }^{25}$. Other frequently used methods are based on Lewis bases such as amine molecules which complex with BN and 
trigger exfoliation ${ }^{26}$. BN nanosheets are also prepared by bottom up approach using chemical vapor deposition technique, and top down methods like scotch tap method and ball milling ${ }^{27}$.

The boron nitride based nanostructures has been widely studied as a nano vector to carry drug and biological molecules, in tissue engineering constructs and in boron neutron capture therapy ${ }^{28-30}$. The BN nanosheets and BN nanotubes (BNNT) are non-toxic to cells and polymer functionalized $\mathrm{BN}$ are highly dispersive in aqueous and organic solvents ${ }^{26,31-32}$. Ciofani et al. reported that poly-L lysine functionalized BNNT effectively conjugates fluorescent markers (quantum dots) and targeting moieties (folic acid) thus exhibiting good dispersing ability and cytocompatibility ${ }^{33-35}$. Li et al. proved that BNNT enhances the differentiation of mesenchymal stem cells into osteoblasts ${ }^{36}$. Biomolecules like DNA and ferritin are also effectively immobilized on BNNT through non covalent interaction ${ }^{37}$. The quantity of linked biomolecules and drugs can be improved by covalent functionalization using amine grafted $\mathrm{BNs}^{38}$. In vivo studies of intravenously injected polymer functionalized (Glycol chitosan, Gum arabic) BNNT also evidenced its biocompatibility ${ }^{39-40}$. Hence, the literature clearly evidences that $\mathrm{BN}$ nanosheets and $\mathrm{BN}$ grafted with various functional groups are cytocompatible and can be employed for biomedical application ${ }^{32,41}$. Conjugation of BN with bio polymers also found application other than biomedical; for instance, Biscarat et al. reported that BN/gelatin composites possess also excellent gas barrier property ${ }^{20}$.

The fibers produced from electrospinning exhibits porous structure and high surface area that allow the proteins adsorption. These properties are essential to create favorable microenvironment for the cell attachment. It possesses also suitable architecture for cell binding, proliferation and tissue regeneration ${ }^{42}$. Hence, synthesizing scaffolds mimicking the extracellular matrix $(\mathrm{ECM})$ is very essential to enhance biological response. For example, the presence of highly organized fibers of collagen type I ECM is essential to differentiate osteoprogenitor cells into mature osteoblasts ${ }^{43}$. The electrospinning is an advantageous technique 
for the fabrication of ECM-like fibrous mats. Schindler et al. reported that the polyamide electrospun nanofibers promote the in vivo-like organization of NIH3T3 fibroblasts and rat kidney cells ${ }^{44}$. Yoshimoto et al. reported that polycaprolactone electrospun nanofibers possess enhanced mineralization and collagen type I deposition after seeding with mesenchymal stromal cells ${ }^{45}$. In vivo studies of PCL electrospun nanofibers also possess multilayers of osteoblast like cells, woven bone like appearance, osteocyte like cells embedded in mineralized matrix ${ }^{46}$. Kim et al. reported that gelatin-hydroxyapatite nanofibers improve bone derived cellular activity ${ }^{17}$. The electrospun fibers of gelatin and polyaniline are found to be a prominent biomaterial for cardiac and neuronal tissue engineering application ${ }^{47}$. Hence this literature clearly evidences that electrospun nanofibers are excellent substitutes to restore and improve the biological activity.

The goal of this paper is to improve the mechanical properties of gelatin electrospun fibers using $\mathrm{BN}$ reinforcement without compromising the biocompatibility of gelatin. This is the first study which $(i)$ reports the synthesis of BN reinforced gelatin nanofibers with bioactive properties, (ii) analyses the biological properties of exfoliated $\mathrm{BN}$ incorporated in gelatin nanofibers, (iii) quantifies the concentration of $\mathrm{BN}$ suitable to enhance the mechanical properties of gelatin ESM and (iv) analyzes cell attachment and proliferation on these ESM and (v) studies the influence of BN concentration on osteoblast gene expression.

\section{EXPERIMENTAL}

\section{Materials}

Type A Gelatin (48722-500G-F) obtained from porcine skin (gel strength170-195 g Bloom), glacial acetic acid, ethanol and 25\% glutaraldehyde (GTA), phosphate buffered saline (PBS) (P44717) tablets, and MTT ((3-(4, 5-Dimethylthiazol-2-yl)-2, 5-diphenyl tetrazolium 
bromide) (Sigma -M2128), are purchased from Sigma Aldrich. BN powder (95294, 4-7 $\square \mathrm{m}$ ) is purchased from HC STARK. The following chemicals; Dimethyl sulphoxide (DMSO) (BDH prolab 23486.297), fetal bovine serum (FBS) (Eurobio CVFSVF00-01), penicillin/Streptomycin (Gibco 15140-122), 0.05\% Trypsin-EDTA (Gibco 25300-054), are used without further purification.

\section{Preparation of spinning solution}

A solvent with high vapor pressure at room temperature is essential for electrospinning. Indeed, to avoid fiber coalescence, the solvent must evaporate from the fibers before it reaches the collector plate. Since water shows poor vapor pressure, acetic acid is used as a solvent. The gelatin $(20 \% \mathrm{~W} / \mathrm{V})$ solution is prepared by dissolving gelatin in glacial acetic acid under magnetic stirring at $60^{\circ} \mathrm{C}$ for 2 hours. BN powder $(0.1,1$ and $5 \%(w / v))$ is added to gelatin solutions and treated with an ultrasonic probe system (SONOPULS HD 3100) for one hour ( 1 second pulse "on" and 0.5 second "off") with $60 \%$ amplitude to prepare a gelatin/BN dispersion. The resultant dispersion is centrifuged at $500 \mathrm{rpm}$ for 30 minutes to obtain the stable dispersion of gelatin/BN in the supernatant.

\section{Electrospinning of gelatin/BN fibers}

The stable gelatin/BN dispersion obtained from the centrifugation is loaded in a $10 \mathrm{~mL}$ syringe. A syringe pump (KDS 100) is used to feed the solution through the needle $(0.7 \mathrm{~mm}$ in diameter). The solution flow rate is controlled to $0.5 \mathrm{~mL} \mathrm{~h}^{-1}$ and $25 \mathrm{kV}$ supplied using HPx 600605 generator (Physical Instruments) ${ }^{48}$. A piece of aluminum foil wrapped around the rotating machine is used to collect the fibers at $400 \mathrm{rpm}$ speed. The electrospinning is carried out $35^{\circ} \mathrm{C}$ at ambient air atmosphere. The fibers prepared using $20 \%$ gelatin are denoted as $0 \mathrm{G}$ 
and the nanofibers prepared using various BN/gelatin weight fraction such as $0.1,1$ and $5 \%$ are referred as $0.1 \mathrm{G}, 1 \mathrm{G}, 5 \mathrm{G}$ respectively.

\section{Cross-linking of ESM}

The collected mats are cut into uniform size of $5 \times 5 \mathrm{~cm}^{2}$, and dipped into a $1 \%$ glutaraldehyde (GTA) solution at $37^{\circ} \mathrm{C}$ for $24 \mathrm{~h}$. The $1 \%$ GTA solution is prepared from $25 \%$ (V/V) GTA stock solution using $96 \%$ ethanol as a solvent. The cross-linked fibers are separated out after 24 h, washed with PBS (phosphate buffered saline) and the neutralization of the unreacted GTA is performed with $10 \%$ glycine solution. The washed samples are dried at $37^{\circ} \mathrm{C}$ for $24 \mathrm{~h}$. The cross-linked $0 \mathrm{G}, 0.1 \mathrm{G}, 1 \mathrm{G}$ and $5 \mathrm{G}$ are denoted as $0 \mathrm{GC}, 0.1 \mathrm{GC}, 1 \mathrm{GC}$ and $5 \mathrm{GC}$ respectively.

\section{Characterization of uncross-linked and cross-linked ESM}

The FTIR spectrum of cross-linked ESM is recorded by NEXUS instrument, equipped with an attenuated total reflection (ATR) accessory in the frequency range of $600-4000 \mathrm{~cm}^{-1}$. The FTIR spectrum is scanned at $1 \mathrm{~cm}^{-1}$ resolution and the signals are averaged from 32 scans. The XRD patterns of gelatin/ $\mathrm{BN}$ mats are recorded using $\mathrm{CuK} \alpha$ radiation, $2 \Theta$ range of $3-70^{\circ}$ and a step rate of $0.02^{\circ}$ per second, using the PANalytica Xpert powder XRD system'.

The stability of the cross-linked ESM is tested by equilibrating the $2 \times 2 \mathrm{~cm}^{2}$ films under 0.01M phosphate buffered saline (PBS) (pH $7.410 \mathrm{~mL}$ ) for 24 hours. Then, the ESM are removed from the PBS, washed with deionized water and dried at $37^{\circ} \mathrm{C}$. The morphology of the uncross-linked and cross-linked ESM is observed using HITACHI S4800 scanning electron microscopy system. The mats are coated with platinum using an ion sputter coater 
before SEM observations. Transmission electron microscopy (TEM) study of the samples is performed using HRTEM JEOL ARM 200F electron microscope, working in scanning mode at an accelerating voltage of $200 \mathrm{kV}$. Fibers are electrospunned on a commercially available $\mathrm{Cu}$ grid with 300 mesh and cross-linked using 1\% GTA.

Mechanical properties of the cross-linked BN reinforced ESM are characterized using the dynamic mechanical analysis system 'Metravib 50N' at controlled force mode. Fiber mats of dimensions $3 \mathrm{~cm}$ length, $1 \mathrm{~cm}$ breadth, $0.15 \mathrm{~mm}$ thick are clamped between the tension film clamps. Stress-strain graph is recorded at $0.05 \mathrm{~N} / \mathrm{s}$ ramp rate. Linear elastic region from the stress-strain graphs is used to calculate the Young's modulus from at least 4 trials and the average results are reported.

The cross-linked ESM is analyzed using a differential scanning calorimeter DSC (TA Instruments 2920), equipped with a RCS90 cooling system. The samples are accurately weighed $(\approx 3 \mathrm{mg})$ in an aluminum TA pan and sealed. An empty sealed pan is used as a reference. The samples are cooled at $-40{ }^{\circ} \mathrm{C}$ and then heated up to $250{ }^{\circ} \mathrm{C}$ with a heating rate of $100{ }^{\circ} \mathrm{C} \min ^{-1}$ following the procedure described by Biscarat et al. ${ }^{20}$. The percentage renaturation level of the gelatin triple helix is calculated from the ratio between the denaturation enthalpies of both cross-linked gelatin ESM and pure porcine skin collagen $(\Delta \mathrm{H}$ denatured collagen $=47.8 \mathrm{~J} / \mathrm{g})^{49-50}$. The thermogravimetric analysis (TGA) of the samples is performed using TA instruments TGA G500 under oxygen flow of $60 \mathrm{~mL} \mathrm{~min}{ }^{-1}$. The samples are heated up to $700{ }^{\circ} \mathrm{C}$ at a heating rate of $10{ }^{\circ} \mathrm{C} \mathrm{min}-1$ and equilibrated for 60 minutes at 700 ${ }^{\circ} \mathrm{C}$ for complete degradation of gelatin.

Biomineralization is carried out using the 1.5x simulated body fluid (SBF). The latter solution is prepared using the standard protocol described by Kokubo et al. ${ }^{51}$. The ESM is cut into $2 \times 2$ 
$\mathrm{cm}^{2}$ and equilibrated to SBF solution. The new SBF solution around the vicinity of the samples is introduced periodically after 24 hours.

Biodegradation of the cross-linked ESM is recorded using collagenase I enzyme at various concentrations $\left(0.02,0.5,5\right.$ or 50 units. $\left.\mathrm{mL}^{-1}\right)$. A control experiment is performed to understand the degradation of the ESM in PBS. The collagenase solutions are prepared from a 0.2 M PBS at pH 7.4. Accurately weighed samples are placed in a vial containing $1 \mathrm{~mL}$ of collagenase solution. The collagenase solution is replaced with fresh collagenase solution at 3 days interval. The samples are recovered at different times, washed, dried at $50{ }^{\circ} \mathrm{C}$ and weighted. The percentage of ESM degradation is calculated by comparing the initial weight before degradation and the final weight of the sample after degradation.

\section{Cell culture}

Human HOS osteosarcoma cells are cultured using DMEM (Dulbecco's modified eagle medium) (Gibco 31331-028) medium with $10 \%(\mathrm{~V} / \mathrm{V})$ fetal bovine serum (FBS) (Eurobio CVFSVF00-01) and 1\% (V/V) penicillin/streptomycin (Gibco 15140-122) at $37^{\circ} \mathrm{C}$ in $5 \%$ $\mathrm{CO}_{2}$. The cells are maintained in $10 \mathrm{~cm}$ diameter Petri dishes and passages with $0.05 \%$ Trypsin-EDTA (Gibco 25300-054).

\section{Cell viability assay and fluorescent staining}

The ESM (6 mm diameter circle) is exposed to UV light ( $\lambda=254 \mathrm{~nm}$ for 1 hour) for sterilization. It is washed with PBS and the ESMs are allowed in DMEM for 30 mins. The HOS cells are plated at $2 \times 10^{3}$ cells/well . It is allowed to attach on the plates for 24 hours and the samples are positioned on top of the cells after 24 hours. The cell viability at different 
periods (1, 4 and 8 days) is investigated using MTT ((3-(4,5-Dimethylthiazol-2-yl)-2,5diphenyl tetrazolium bromide) assay. Shortly, $100 \mu \mathrm{L}$ of the $0.05 \mathrm{mg} \mathrm{mL}^{-1}$ of MTT solution is added onto the cells and incubated for $4 \mathrm{~h}$. The purple colored formazan crystals are dissolved using $100 \mu \mathrm{L}$ of DMSO (BDH Prolab 23486.297) and the absorbance is recorded at $560 \mathrm{~nm}$ using multiskan plate reader (thermos, USA).

Proliferation of cells on the ESM is recorded by epifluorescence imaging microscope system (DM6000 Leica). The concentrated cells $\left(2 \times 10^{3}\right.$ cells/sample) are allowed to attach for 30 minutes and then complete DMEM is supplied. The proliferation of the cells on the ESM at various periods is monitored using fluorescent imaging. For imaging, the cells attached on the samples are fixed by $4 \%$ formaldehyde for 20 minutes and stained with Hoechst 33342. Cells attached on the ESM are recorded using SEM. Cells cultured for four days on the ESM are fixed using $2.5 \%$ of GTA for 2 hours. Samples are washed and dehydrated using serial concentration of ethanol $(30 \%, 50 \%, 70 \%, 90 \%$ and absolute ethanol). The samples are further treated with $1 \mathrm{~mL}$ of hexamethyldisilazane to dry the sample. Samples are further coated with platinum using an ion sputter coater and the morphology of the cells attached on the ESM is recorded using SEM.

\section{Real-time qPCR}

RNAs were extracted from cells attached and cultured on the samples with Quick RNA ${ }^{\mathrm{TM}}$ Miniprep kit (Zymo Research) according to the manufacturer's instructions. The extracted RNA $(1 \mu \mathrm{g})$ and qScript cDNA master mix (Quanta Bioscience) is used to synthesis cDNA. The quantitative mRNA expression is determined by real time PCR (qPCR), SYBR Green Mix (VWR) with the LightCycler 480 (Roche Applied Science). The final reaction volume is 10 $\mu \mathrm{l}$, in which $0.5 \mu \mathrm{l}$ of each primer $(25 \mu \mathrm{M}), 2.5 \mu \mathrm{l}$ of $\mathrm{H}_{2} \mathrm{O}, 5 \mu \mathrm{l}$ of the SYBR green master 
mix, and $2 \mu \mathrm{l}$ of the template at a 1:5 dilution. The mixtures are preincubated at $95^{\circ} \mathrm{C}$, the experiment consists of 40 cycles in which each cycle consists of 15 seconds each at $95^{\circ} \mathrm{C}, 45$ seconds at $60^{\circ} \mathrm{C}$, and 30 seconds at $72^{\circ} \mathrm{C}$, followed by melting curves analysis to eliminate non-specific amplification products. Relative mRNAs expression levels for the interested gene are quantified through normalization with TBP housekeeping gene. The primer sequences are listed in the Table 1.

Table 1. The primers sequence of osteoblast genes

Primer Forward sequence Reverse sequence

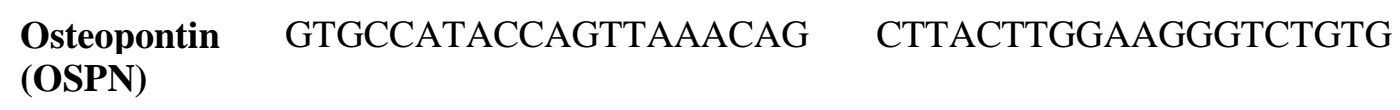

\section{Alkaline phosphatase (ALP) activity}

HOS cells $\left(8 \times 10^{3}\right.$ cells/well) are cultured on the cross-linked ESM for 8 days. The cells are washed with PBS and lysed using $50 \mu \mathrm{L}$ of Tris $\mathrm{HCl}(0.1 \mathrm{M}, \mathrm{pH} 8)$ with $0.1 \%(\mathrm{v} / \mathrm{v})$ triton $\mathrm{X}$ 100. The ALP activity is analyzed by quantifying the concentration of p-nitrophenol from pnitrophenyl phosphate (PNPP). The cell lysate $(10 \mu \mathrm{L})$ is incubated with PNPP $(50 \mu \mathrm{L})$ (Sigma N1891) at $37^{\circ} \mathrm{C}$ for $60 \mathrm{~min}$ and the amount of p-nitrophenol is estimated by recording the absorbance at $405 \mathrm{~nm}$. The percentage ALP activity of the cells cultured along the ESM is calculated by comparing the ALP activity of cells cultured on tissue culture plates. 


\section{RESULTS AND DISCUSSION}

\section{Chemical and structural characterization of ESM}

Various ESMs (elaborated with 0.1, 1 and $5 \% \mathrm{BN}$ weight fraction and referred as uncrosslinked $0.1 \mathrm{G}, 1 \mathrm{G}$ and $5 \mathrm{G}$ respectively) is generated as described in the Materials and Method section. The synthesized ESM are highly soluble in PBS. Hence, to improve the stability of the electrospun fibers, the fibers are cross-linked with $1 \%$ GTA and referred as GC, 0.1GC, $1 \mathrm{GC}$ and $5 \mathrm{GC}$ respectively.

In order to understand the gelatin chains organization and the interactions of $\mathrm{BN}$ with gelatin during the ESM fabrication, FTIR spectra are first recorded. The FTIR spectra of uncrosslinked and cross-linked electrospun fibers are depicted in the Figure 1 (a-b) respectively. The peak at about $3280-3287 \mathrm{~cm}^{-1}$ is due to the presence of amide A. The characteristic peaks of amide I, II and III are observed at 1627-1632, 1527-1534 and 1236-1241 $\mathrm{cm}^{-1}$ respectively in synthesized and cross-linked ESM. The low intensity peak observed at $2945 \mathrm{~cm}^{-1}$ shows asymmetric $\mathrm{CH}_{2}$ stretching modes of gelatin, whereas the asymmetric and symmetric stretching modes of carboxylates group of gelatin are observed at 1332 and $1406 \mathrm{~cm}^{-1}$ respectively ${ }^{52}$. The shift in the symmetric stretching band of carboxylates groups towards the lower wavenumber from 1406 to $1385 \mathrm{~cm}^{-1}$ in $1 \mathrm{G}, 5 \mathrm{G}$ and the broadening of the band observed at $1406,1385,1374 \mathrm{~cm}^{-1}$ in $0.1 \mathrm{G}, 1 \mathrm{G}, 5 \mathrm{G}$ respectively, suggest that carboxylates have strong interaction with the boron nitride nanosheets and such an interaction facilitates the exfoliation of BN. The presence of amide I and II peaks provides evidences for the presence of gelatin chains. The two major peaks of BN observed at 1271 and $763 \mathrm{~cm}^{-1}$ as 
depicted in Figure1 (a) are assigned to the B-N stretching and out of plane bending of B-N in hexagonal ring respectively ${ }^{53}$.
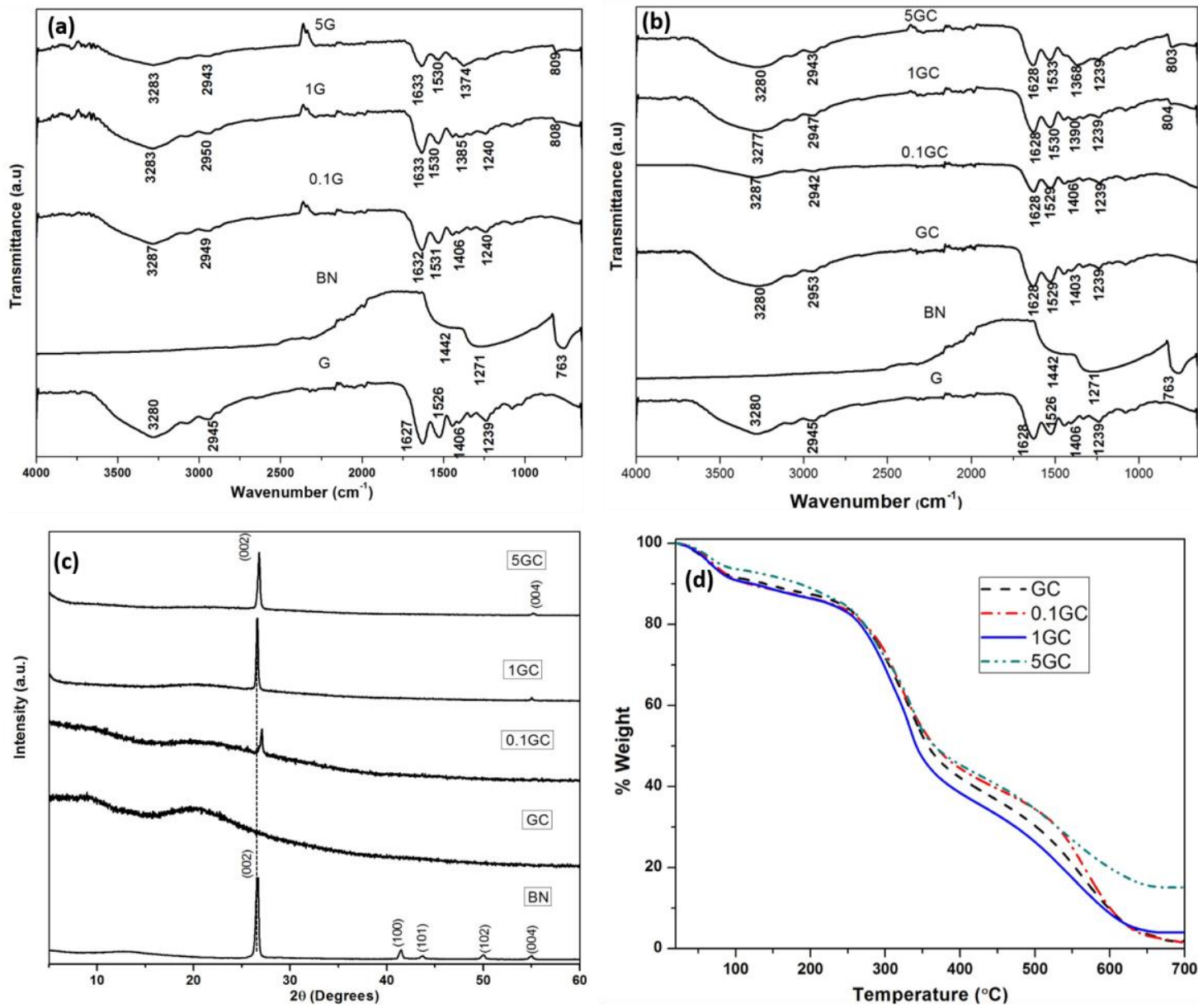

Figure 1. FTIR spectrum of (a) uncross-linked, (b) cross-linked ESMs, (c) XRD graphs and (d) TGA graphs of cross-linked ESM.

The effect of gelatin on the exfoliation of BN and the crystallinity of the exfoliated boron nitride are analyzed using the X-ray diffraction (XRD) patterns of the cross-linked ESM. The XRD patterns are depicted in the Figure 1 (c). The 0.1 GC, $1 \mathrm{GC}$ and $5 \mathrm{GC}$ nanofibers shows 2 peaks at $2 \Theta=26.6^{\circ}$ and $55^{\circ}$ corresponds to (002) and (004) planes of $\mathrm{BN}$ respectively. The peaks observed at $2 \Theta=41.5^{\circ}, 43.7^{\circ}$ and $50^{\circ}$ correspond to (100), (101) and (102) planes of $\mathrm{BN}$ respectively disappear, evidencing the efficient exfoliation of $\mathrm{BN}$ in $0.1 \mathrm{GC}, 1 \mathrm{GC}$ and 
$5 \mathrm{GC}$ and the reinforcement of the gelatin ${ }^{20}$. The broadband centered to $2 \Theta=20^{\circ}$ is also due to the presence of random coiled conformation of gelatin.

\section{Thermal analysis}

The effects of the preparation route and $\mathrm{BN}$ addition on the renaturation level of gelatin, i.e. the triple-helix content, are evaluated through differential scanning calorimeter (DSC) analyses. The helix-coil transition is characterized by the peak temperature of a first endotherm $\left(\mathrm{T}_{\mathrm{m}}\right)$ and by the melting enthalpy $\left(\Delta \mathrm{H}_{\mathrm{m}}\right)$, as the area over the same peak. At temperatures above $130^{\circ} \mathrm{C}$ a second endotherm is observed and corresponds to the degradation of the protein. This second peak temperature is called degradation temperature $\left(\mathrm{T}_{\mathrm{d}}\right)$.

It has been previously demonstrated ${ }^{54}$ that the triple helix level greatly affects mechanical properties of gelatin films. Higher values of Young's modulus are obtained when the triplehelix content increases. Besides, it is believed that the renaturation of random coil gelatin strands to the collagen-like triple helical structure can only exists if water molecules are included in the crystals formed. The structural water, directly bound to the gelatin strands by hydrogen bonds is responsible of the stabilization of the triple helical gelatin structure. In this study, gelatin is first dissolved in anhydrous solvent, glacial acetic acid, before BN addition, sonication, centrifugation and electrospinning. Thus, the renaturation of gelatin is not favored in those conditions. The triple helix percentage of the gelatin is calculated from the melting enthalpy. The thermal properties of type A gelatin powder (G powder), ESM fabricated using unsonicated gelatin solution (UG), uncross-linked and cross-linked ESM and the corresponding calculated triple helix levels are listed in Table 2. 
Table 2. Denaturation $\left(\mathrm{T}_{\mathrm{m}}\right)$ and degradation $\left(\mathrm{T}_{\mathrm{d}}\right)$ temperatures, and triple helix percentage of gelatin extracted from DSC data

\begin{tabular}{ccccc}
\hline Sample & $\mathbf{T}_{\mathbf{m}}\left({ }^{\circ} \mathbf{C}\right)$ & $\mathbf{T}_{\mathbf{d}}\left({ }^{\circ} \mathbf{C}\right)$ & $\Delta \mathbf{H}_{\mathbf{m}}(\mathbf{J} / \mathbf{g})$ & Triple helix \\
& & & & level \% \\
\hline G powder & $80 \pm 1$ & $160 \pm 1$ & $4.0 \pm 0.4$ & $8.4 \pm 0.8$ \\
Un sonicated G & $87 \pm 3$ & $161 \pm 5$ & $4.3 \pm 0.1$ & $8.9 \pm 0.2$ \\
$0.1 \mathrm{G}$ & $86 \pm 1$ & $143 \pm 3$ & $0.6 \pm 0.05$ & $1.3 \pm 0.1$ \\
$1 \mathrm{G}$ & $93 \pm 1$ & $156 \pm 3$ & $1.0 \pm 0.3$ & $2.0 \pm 0.6$ \\
$5 \mathrm{G}$ & $81 \pm 1$ & $144 \pm 12$ & $2.0 \pm 0.1$ & $4.2 \pm 0.2$ \\
$\mathrm{GC}$ & $92 \pm 1$ & $140 \pm 7$ & $2.1 \pm 0.2$ & $4.5 \pm 0.3$ \\
$0.1 \mathrm{GC}$ & $87 \pm 1$ & $161 \pm 3$ & $1.6 \pm 1.2$ & $3.3 \pm 2.5$ \\
$1 \mathrm{GC}$ & $94 \pm 3$ & $146 \pm 4$ & $2.4 \pm 0.1$ & $5.0 \pm 0.2$ \\
$5 \mathrm{GC}$ & $75 \pm 2$ & $148 \pm 8$ & $2.7 \pm 0.1$ & $5.6 \pm 0.2$ \\
& $87 \pm 9$ & $134 \pm 6$ & $3.0 \pm 0.1$ & $6.3 \pm 0.2$ \\
\hline & & & & \\
\hline & & & & \\
\hline
\end{tabular}

Denaturation and degradation temperature ranges are from 80 to $94^{\circ} \mathrm{C}$, and from 134 to $161^{\circ} \mathrm{C}$ respectively. Kruskal-Wallis tests are performed using the computer program $\mathrm{R}$ with a significance level set at $\mathrm{p} \leq 0.05$ for $\mathrm{BN}$ reinforced and gelatin samples. They show that neither the formulation nor the process has a significant influence on both degradation and denaturation temperature. However, increase in denaturation enthalpy with rising $\mathrm{BN}$ content compare with GC $(\mathrm{p}<0.05)$ demonstrates the influence of the preparation route and the formulation on the obtained values. 
Firstly, very low triple helix levels could be calculated, meaning the presence of insignificant proportion of the helical conformation of gelatin in the anhydrous solvent involved in this study. Only a small part of gelatin chains are organized in helical conformation. Indeed, 9\% triple helix level is determined for ESM fabricated using unsonicated gelatin solution (UG). This value is very close to the results obtained on gelatin powder, and has to be related with the residual water content still present with the gelatin and acting as structural water. Indeed no preliminary drying step is conducted on gelatin raw material. The dry matter determination on type A gelatin reveals that actually there is $8 \%$ residual water in the powder. This can explain the existence of a part of gelatin chains in triple helix conformation. Secondly, results display that sonication drastically decreases triple helix level compare to ESM fabricated without sonicated gelatin solution. This observation is consistent and has to be related to the fragmentation of gelatin chains in ultrasonic bath ${ }^{18}$. The ultrasonic waves act on the solvent and generate the rapidly growing micro bubbles. The disruption of these bubbles generates strong shear forces which damage inter and intra molecular forces of polymers and are responsible for the low degradation temperature of sonicated gelatin $\left(143 \pm 3{ }^{\circ} \mathrm{C}\right)$ compare to non-sonicated gelatin $\left(161 \pm 5{ }^{\circ} \mathrm{C}\right)(\text { Table } 2)^{55}$. Finally, increasing the BN concentration enhances the triple helix level of collagen (1.3 to $4.5 \%)$. This is due to the intercalation of gelatin between $\mathrm{BN}$ nanosheets. The nanosheets restrict the gelatin and the movement segment is controlled ${ }^{20}$. The cross-linking step increases $\Delta H_{m}$. This may be attributed to ESM washes with PBS, allowing the absorption of some water molecules inside the gelatin matrix. To conclude, the as-prepared ESMs display a very low level of gelatin triple helix, which could also affect their mechanical properties and degradation temperature.

The thermal stability and the influence of the concentration of BN on the cross-linked ESM are quantified using the TGA analyses (Figure 1d)). The weight loss (9-10\%) observed below $108^{\circ} \mathrm{C}$ is due to the solvents (residual acetic acid and structural water of gelatin). The second 
major weight loss observed between $200-400^{\circ} \mathrm{C}$ shows the degradation of gelatin molecules. The third major weight loss observed from around $520^{\circ} \mathrm{C}$ is due to the thermochemical decomposition of remaining organic content. The $1 \mathrm{GC}$ samples exhibits strong interaction with the $\mathrm{BN}$, which results to the high thermal stability of the ESM, whereas, high concentration of non-exfoliated $\mathrm{BN}$ shows poor interaction. The gelatin undergoes complete decomposition below $700{ }^{\circ} \mathrm{C}$, the remaining residues are due to $\mathrm{BN}$, which are quantified gravimetrically and listed in the Table 3. It is evidenced that the $\mathrm{BN}$ added at higher concentrations (5 and 20\%) is not completely dispersed in the gelatin. During the centrifugation step, the remaining unexfoliated $\mathrm{BN}$ is separated out.

Table 3. Composition of gelatin, solvent and boron nitride present in the cross-linked ESM extracted from the TGA graphs

\begin{tabular}{llllll}
\hline Sample & Gelatin & Solvent & Residues after & $\%$ & BN \\
& $(\%)$ & $(*)(\%)$ & combustion & added & in \\
& & & $(\%)$ & solution & \\
\hline GC & $89 \pm 1$ & $9 \pm 1$ & $2 \pm 1$ & 0 \\
0.1GC & $89 \pm 1$ & $10 \pm 1$ & $1 \pm 0.1$ & $0.5 \pm 0.1$ \\
1GC & $86 \pm 1$ & $10 \pm 1$ & $4 \pm 1$ & $5 \pm 1$ \\
5GC & $79 \pm 1$ & $7 \pm 1$ & $14 \pm 1$ & $20 \pm 1$ & \\
\hline
\end{tabular}

(*) acetic acid and structural water

\section{Morphological studies of the ESM}

Scanning electron microscopy is used to analyze the morphology of uncross-linked fibers, the stability of fibrous network on PBS, the effect of cross-linking on the morphology of uncross- 
linked fibers and the size of the electrospun fibers (Figure 2 insert images are higher magnification images of the electrospun fibers). The diameter of the fibers is listed in Table 4.
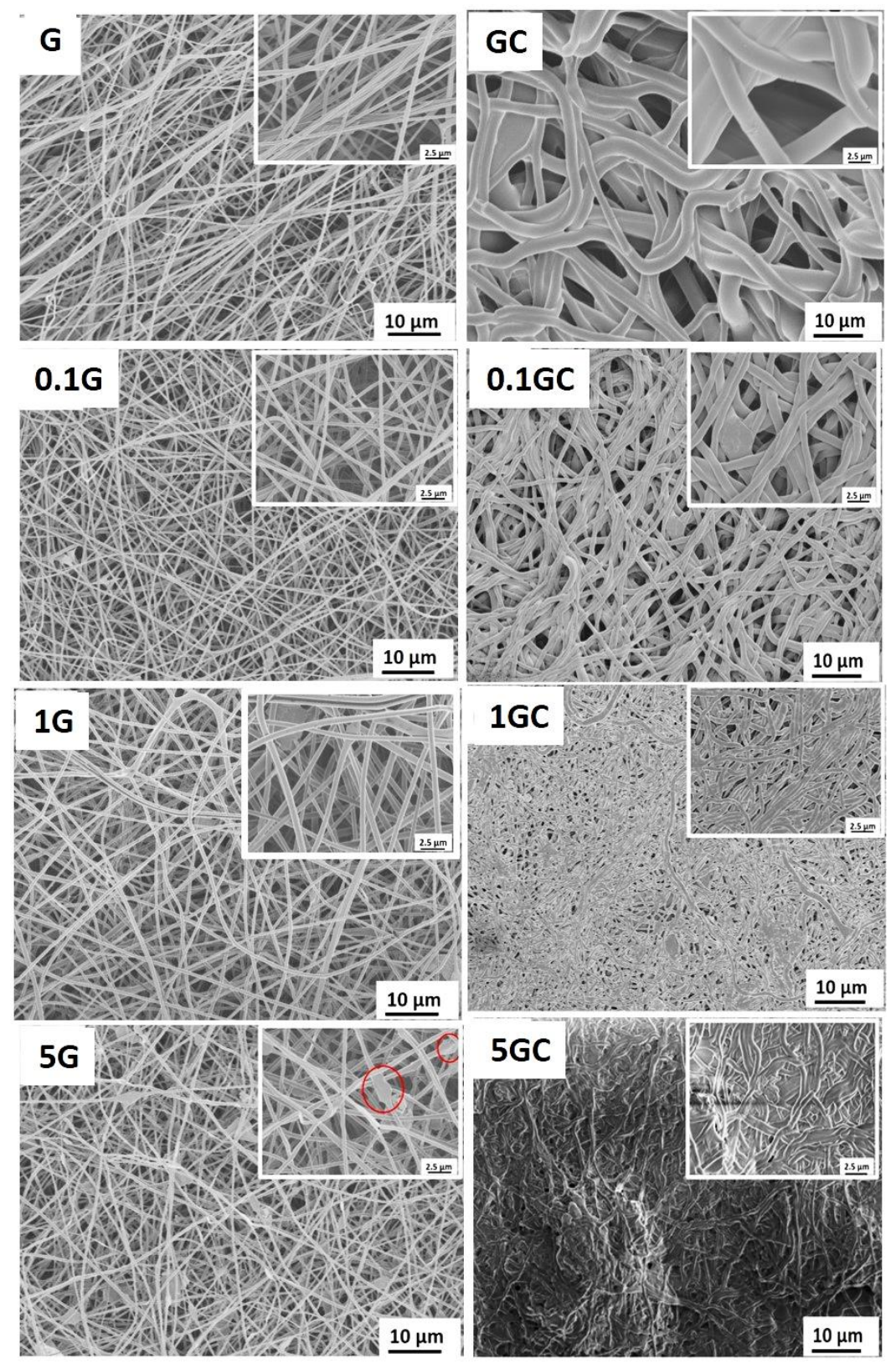

Figure 2. Scanning electron micrograph of uncross-linked ESMs (left panel) and cross-linked (right panel) ESM. 
Table 4. Size of uncross-linked and cross-linked electrospun fibers

\begin{tabular}{cccc}
\hline Sample & $\begin{array}{c}\text { Size of the fibers before } \\
\text { cross-linking }(\mathbf{n m})\end{array}$ & Sample & $\begin{array}{c}\text { Size of the fibers after cross- } \\
\text { linking (nm) }\end{array}$ \\
\hline $\mathbf{G}$ & $1173 \pm 160$ & GC & $2300 \pm 111$ \\
$\mathbf{0 . 1 G}$ & $410 \pm 49$ & $\mathbf{0 . 1 G C}$ & $822 \pm 75$ \\
$\mathbf{1 G}$ & $483 \pm 50$ & $\mathbf{1 G C}$ & $447 \pm 56$ \\
$\mathbf{5 G}$ & $346 \pm 37$ & $\mathbf{5 G C}$ & $581 \pm 60$ \\
\hline
\end{tabular}

The SEM micrograph shows the fibrous morphology of the ESM. The size of the uncrosslinked gelatin fibers decreases from $1173 \mathrm{~nm}( \pm 160)$ to $346 \mathrm{~nm}( \pm 37)$ when the concentration of $\mathrm{BN}$ increases as depicted in Figure 2. The absence of visible grain $\mathrm{BN}$ sheets in $0.1 \mathrm{G}$ and $1 \mathrm{G}$ as shown in the Figure 2 clearly evidences that $\mathrm{BN}$ are reinforced and well exfoliated in the gelatin matrix. TEM image is recorded for cross-linked ESM to understand the BN reinforcement. It clearly proved that the $\mathrm{BN}$ nano sheets are distributed in gelatin electrospun fibrous matrix as shown in Figure 2 (1GC). TEM images depict the smooth fibrous surface whereas $\mathrm{BN}$ plates are oriented along electrospun fibers in 1GC samples. Higher magnification images of electrospun fibers are shown in Figure 3 (inset images). BN nanosheets are easily distinguished inside the Gelatin matrix proving the inclusion of $\mathrm{BN}$ inside the gelatin electrospun fibers. 

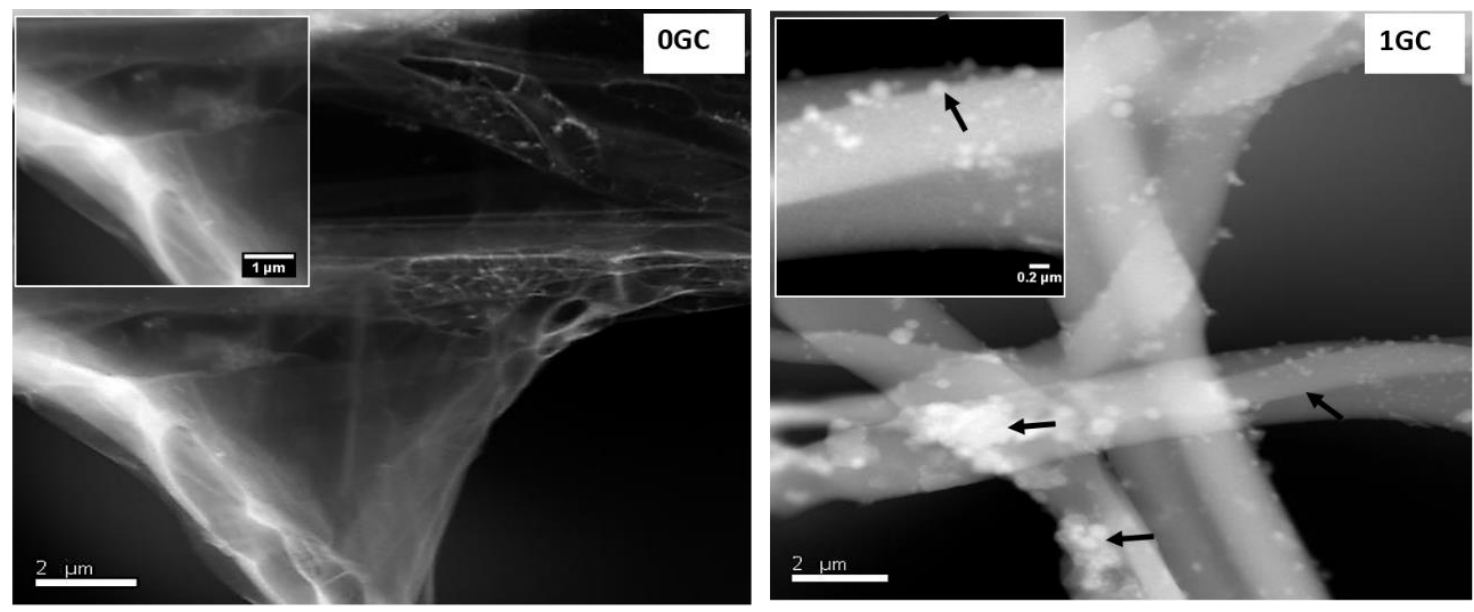

Figure 3. TEM images of the cross-linked ESM (The black arrow indicates the distribution of $\mathrm{BN})$. The insets are higher magnification images.

\section{Mechanical properties of the electrospun nanofibers}

The composite used for the biomedical implant application should withstand high loads. Hence understanding the mechanical properties of the composite is essential for implants application. Mechanical properties of gelatin-based ESM are shown in Figure 4. Siimon et al., reported that the fibers are ordered straight after elastic region, oriented to particular direction and do not slide on each other on applied force. In case of cross-linked fibers, cross-linking bonds are established between gelatin molecules in each nanofiber but also at the intersection of different fibers as evidenced in Figure $2^{56}$. Hence the cross-linked fibers cannot orient to the applied force, structural changes greatly influence at plastic region of cross linked ESMs. So the study is focused on elastic region as well as on understanding the effect of BN addition on elastic modulus. Young's modulus obtained for the 0GC (470 MPa) ESM is in good agreement with the literature data on cross-linked gelatin ESM. ${ }^{57}$ The Young's modulus of the electrospun nanofibers increases with the $\mathrm{BN}$ concentration from $0.1 \mathrm{GC}$ to $5 \mathrm{GC}$. The Young's modulus of 5GC increases 3 fold in comparison to 0GC. Indeed, no significant 
change is observed for tensile stress at break with $\mathrm{BN}$ inclusion. The improved stiffness of the BN/Gelatin ESM in comparison to cross-linked gelatin ESM evidenced the reinforcement of fibers with BN. BN reinforcement with gelatin improves the stiffness of the electrospun fibers in comparison to gelatin electrospun fibers fabricated with synthetic, biopolymers or inorganic material like hydroxyapatite ${ }^{17,58-60}$. Hence, the BN reinforced ESM are promising fillers for the improvement of the mechanical properties of the biopolymer gelatin. In addition, the incorporation of $\mathrm{BN}$ can counterbalance the effects of low level of gelatin triple helix on mechanical properties caused by the use of a non-aqueous solvent.
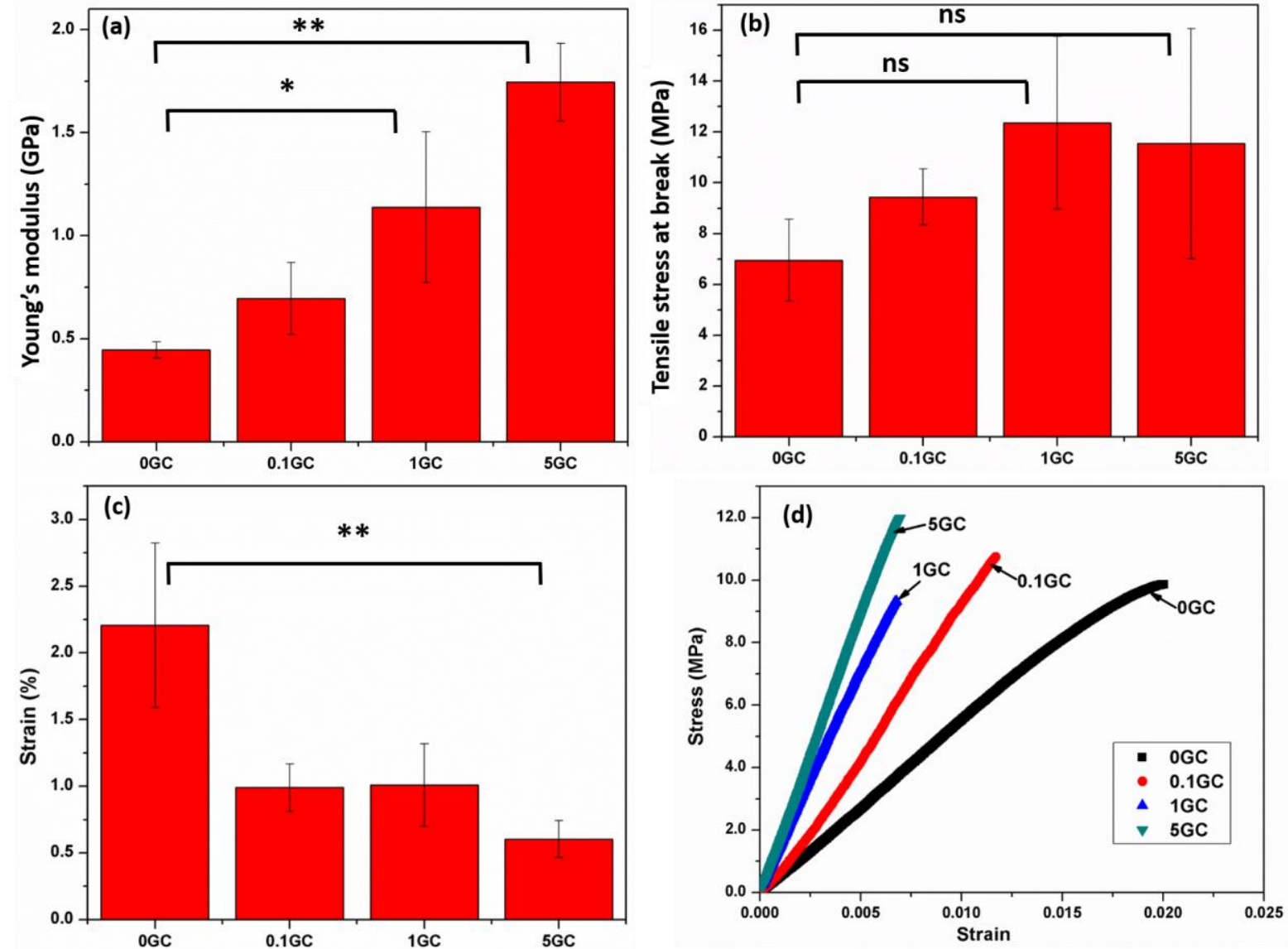

Figure 4. Mechanical property of the ESM with (a) Young's modulus, (b) tensile stress at break, (c) strain at break and (d) stress vs strain graph of the cross-linked ESM (ns = no significance, $\mathrm{p}<0.05=*, \mathrm{p}<0.005=* *)$ 


\section{Biodegradation of the ESM}

Designing biodegradable scaffolds is essential for tissue engineering application. Degradation of the polymer scaffolds is necessary to avoid additional surgery for removing the implant matrix. Hence, the stability and the degradation properties of the ESM in PBS are analyzed using collagenase I enzyme and shown in Figure 5. First, the stability of the ESM is analyzed for 20 days in PBS without collagenase (Figure 5a). The results show that the mats are highly stable in PBS solution. The stability of the different ESM is also observed when low concentration of collagenase I $\left(0.02 \mathrm{U} / \mathrm{mL}^{-1}\right)$ is used for up to 20 days (Figure $\left.5 b\right)$. These data indicate that the ESMs are suitable scaffolds for cell attachment. However, sustained degradation of the ESM is required for prolonged cell growth on the ESM. In order to demonstrate that the different ESMs are degradable in vitro, increasing concentrations of enzyme have been used on a $24 \mathrm{hr}$ period. Full degradation of the different ESMs is obtained at a concentration of $50 \mathrm{U} / \mathrm{ml}$ of collagenase (Figure 5c). Altogether, these results show that the synthesized ESMs are stable in aqueous solution (required to facilitate cell attachment) and enzymatically degradable which are an indispensable property for tissue engineering application. 


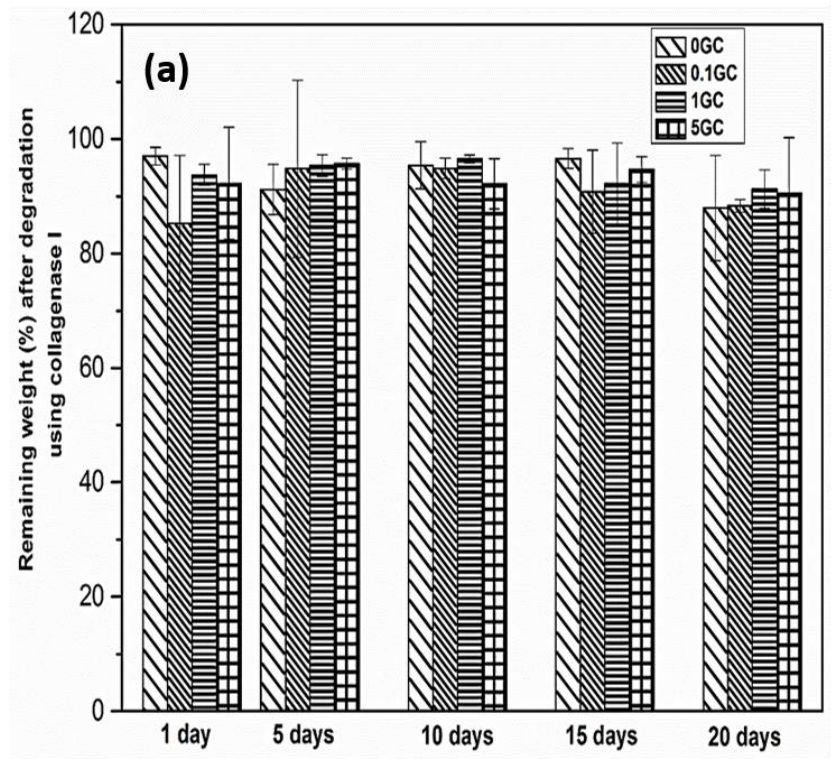

(c)

$0 \mathrm{U} / \mathrm{mL}$
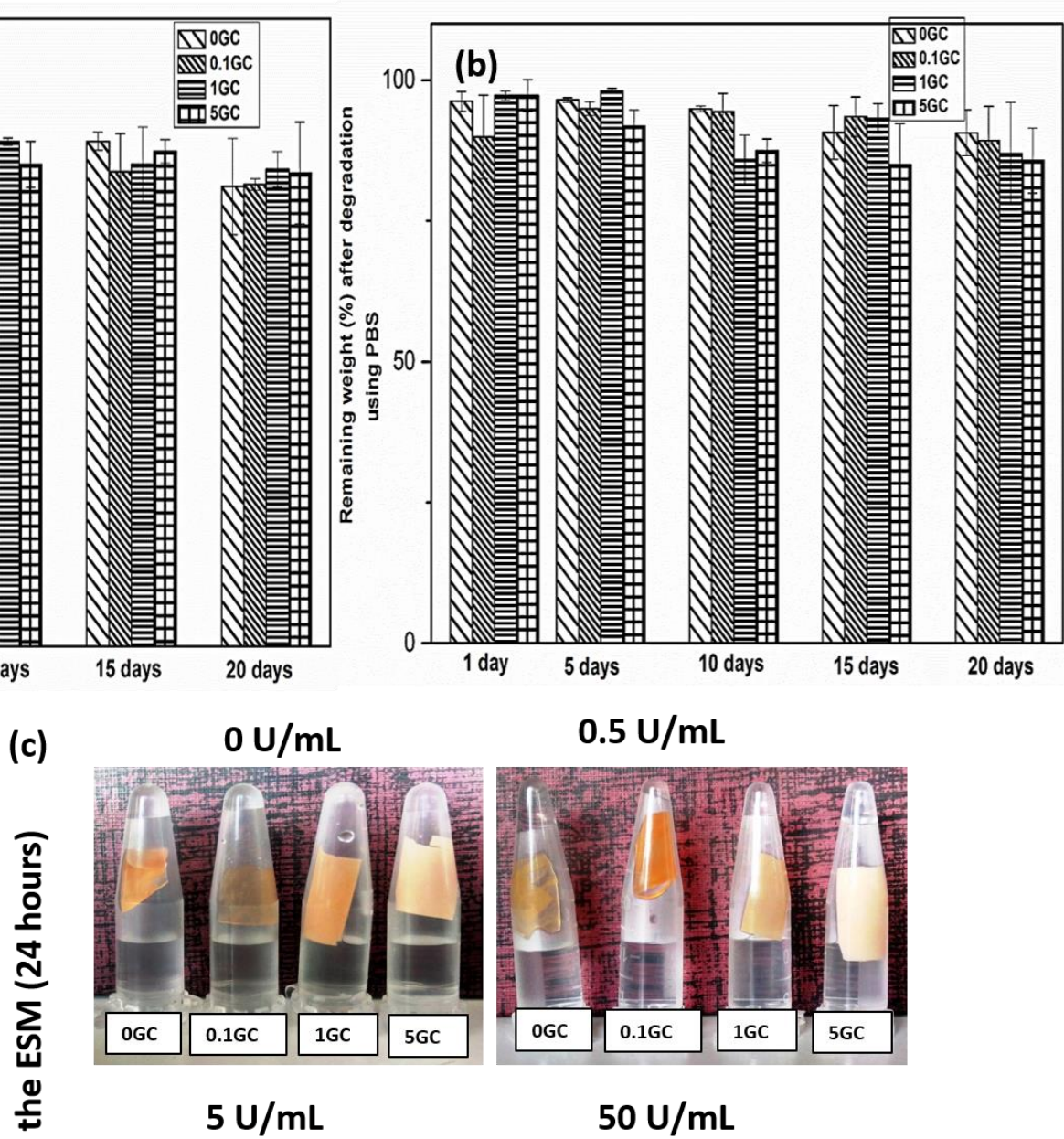

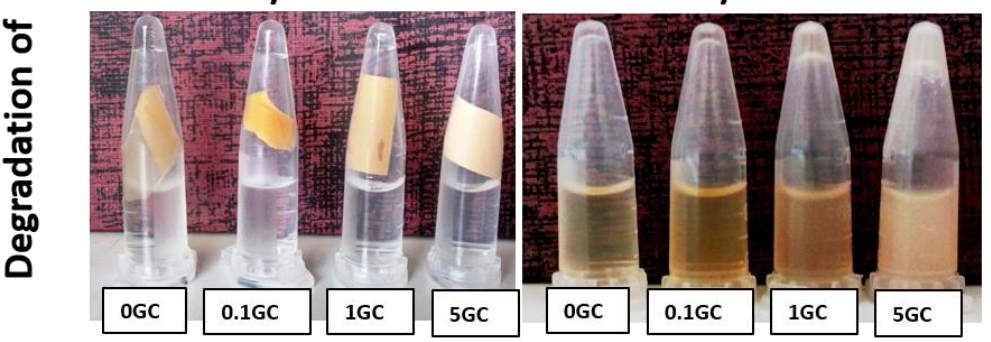

Figure 5. Biodegradation of ESM in (a) PBS, (b) time-course analysis with low concentration of collagenase and (c) dose-response of collagenase.

\section{Biomineralization of the ESM}

Composites showing bioactive properties are essential for bone implant application. The bioactive surfaces develop a hydroxyapatite layer at the surface of the implant materials. Thus the hydroxyapatite layer acts as an intermediate layer between the bone tissue and the 
implant $^{61}$. The intermediate hydroxyapatite layer controls the fibrous capsule formation which induces a negative effect during osteo-integration. In order to study the formation of bioactive layers on the cross-linked ESMs GC, 0.1GC, 1GC and 5GC, the mats are mineralized for 10 days. After the mineralization, mats are denoted as 10DGC, 10D0.1GC, 10D1GC, 10D5GC respectively. The SEM images of the mineralized ESM are shown in the Figure 6. The 10DGC is found to have random mineralization of hydroxyapatite on gelatin fibers (Figure 6a); the smooth surfaces are non-mineralized. The presence of hydroxyapatite is confirmed by XRD analysis and shown in the Figure 7a. The 10D0.1GC and 10D1GC possess the uniform nucleation of hydroxyapatite on the fibers. The hydroxyapatite minerals completely cover the surface of the fibers 10D5GC as evidenced in the insert image of Figure 6d. It is clearly evidenced that increasing the concentration of $\mathrm{BN}$ increases the bioactivity of the gelatin mats significantly. The vacant "p" orbital of the boron atom present in boron nitride is responsible for the Lewis acid nature. Garcia et al. reported that hydroxyapatite is found to possess Lewis base nature ${ }^{62}$. The hydroxyapatite nanocrystals formed from the SBF interact with the BN through Lewis acid-base interaction. Hydroxyapatite mineralization increases along with BN enhancement substantiate the Lewis acid-base interaction. Hence this results shows that BN is highly bioactive and suitable for mineralization of hydroxyapatite. 




Figure 6. Scanning electron micrograph of cross-linked, SBF equilibrated ESM (a) 10DGC,

(b) 10D0.1GC, (c) 10D1GC and (d) 10D5GC

The XRD patterns of the 10 days mineralized GC, $0.1 \mathrm{GC}, 1 \mathrm{GC}$ and 5GC are recorded and shown in Figure 7a. The XRD patterns are in good agreement with the standard JCPDS (090432) data for hydroxyapatite. The formation of hydroxyapatite is induced by the carboxylates groups of gelatin through the interaction of calcium ions in the SBF. The major plane of $\mathrm{BN}$ observed at unmineralized samples (Figure 1c, 0.1GC and 1GC) disappeared on the 10 days mineralized samples (10D0.1GC and 10D1GC). It shows that mineralized hydroxyapatite (Figure 6 (b-c) crystals affect the X-ray penetration, and the BN diffraction disappeared. The appearance of $\mathrm{BN}$ peaks in 10D5GC is due to the flunked un-exfoliated sheets of $\mathrm{BN}$ in gelatin fibers as shown in Figure $2(5 \mathrm{G})$. 

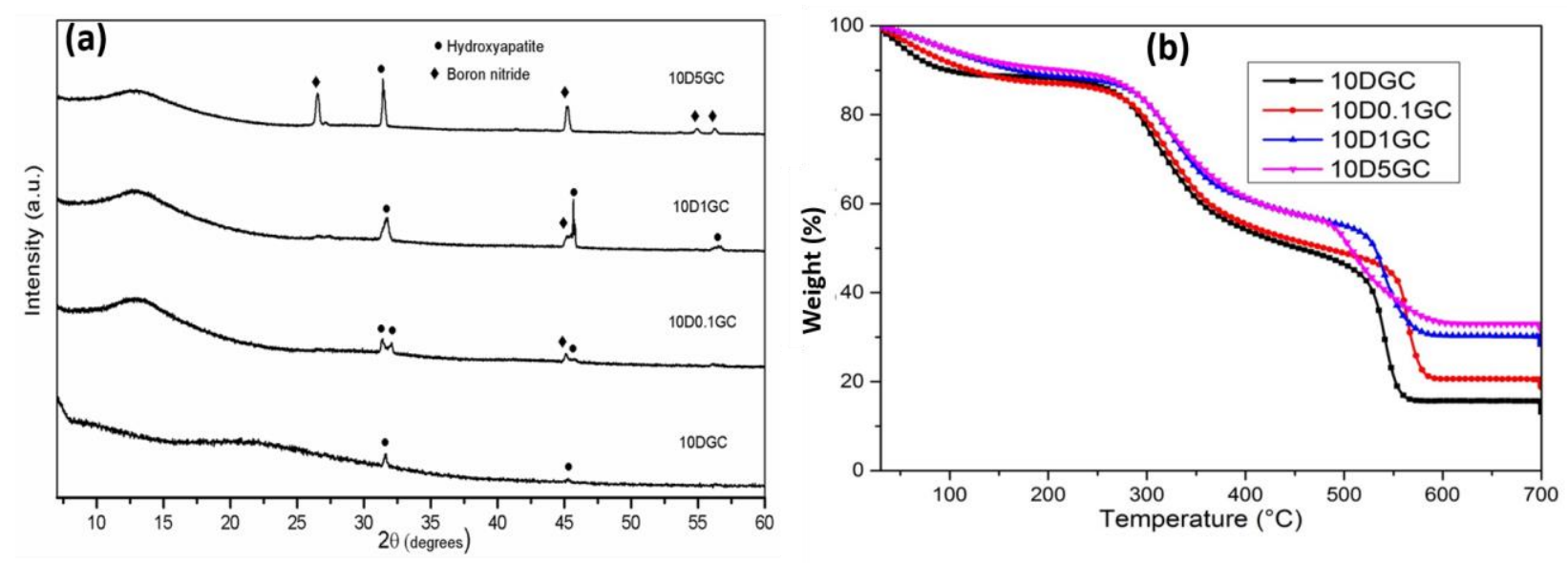

Figure 7. (a) XRD patterns and (b) TGA graphs of cross-linked gelatin and gelatin/BN electrospun fibers with different BN concentrations after mineralizing for 10 days.

Hydroxyapatite is the major inorganic content found in hard tissues like bone and teeth. Hence observing mineralization ability of the ESM and quantifying the concentration of inorganic content is essential. The hydroxyapatite mineralized in GC, $0.1 \mathrm{GC}, 1 \mathrm{GC}$ and 5GC are quantified using TGA analysis and listed in the Table 5 and the graphs are shown in the Figure $7 \mathrm{~b}$. The major weight losses observed from $100{ }^{\circ} \mathrm{C}$ to $600{ }^{\circ} \mathrm{C}$ in mineralized ESM are due to the degradation of gelatin. The presence of $15 \%$ insoluble residues in GC depicts the mineralized hydroxyapatite. It is found that mineralization of hydroxyapatite increases with the BN nanosheets concentration. The uncertainty in the concentration of hydroxyapatite at $5 \mathrm{GC}$ is due to the release of unexfoliated $\mathrm{BN}$ in $\mathrm{SBF}$ solution, flunked between the fibers as depicted in Figure $2(5 \mathrm{G})$. 
Table 5. Concentration of hydroxyapatite mineralized in ESM

\begin{tabular}{cccc}
\hline Sample & Gelatin and solvent & BN (\%) & Hydroxyapatit \\
$(\%)$ & $(\%)$ & e \\
& & & $\%$ \\
\hline GC & $85 \pm 1$ & 0 & 15 \\
0.1GC & $80 \pm 1$ & $0.5 \pm 0.1$ & $19.5 \pm 0.1$ \\
1GC & $70 \pm 1$ & $2.1 \pm 0.1$ & $27.9 \pm 0.1$ \\
5GC & $67 \pm 1$ & $13.2 \pm 0.1$ & $19.8 \pm 0.1$ \\
\hline
\end{tabular}

\section{Cell viability and osteoblast gene expression}

The cross-linked gelatin/BN ESMs show enhanced biomineralization in SBF thus indicating that they might be suitable to increase the mineralization and may represent potent material for bone tissue engineering. Due to high degree of cross-linking, the GTA has been widely used for cross-linking polymer materials ${ }^{63}$. The aldehyde groups of GTA undergo nucleophilic substitution reaction with amine, thiol and imidazole groups of proteins in cells and induce the toxicity. The aldehyde groups of GTA are utilized for cross-linking the gelatin. However, the unreacted aldehyde terminals are neutralized with $10 \%$ glycine and the biocompatibility of cross-linked ESM is investigated using human HOS bone cells, which exhibit osteogenic potential ${ }^{63-64}$. Cell attachment on the ESM is observed by staining the nuclei of the cells since the strong autofluorescence of cross-linked gelatin limits the observation of the actin staining of the cells ${ }^{65}$. The cells attached at 24 hours proliferate on the ESM and reach confluence after 8 days as shown in the Figure 8 . Cell attachment and proliferation on the ESM is not affected by the $\mathrm{BN}$ concentration and by the direct contact with unexfoliated BN in 5GC. Cells attached on the ESM are cultured for four days and fixed 
with GTA. The morphology is then recorded using SEM analysis and shown in Figure 8. SEM images show that the ESM facilitates cell attachment and proliferation irrespective of the $\mathrm{BN}$ concentration. Cells exhibit enhanced spreading and larger area on the 0GC and BN reinforced GC evidence that the ESM are highly biocompatible material suitable for tissue engineering application.

The alkaline phosphatase (ALP) is the dephosphorylating hydrolase enzyme, which hydrolyses pyrophosphate into phosphate. The free phosphate ions increase calcium phosphate mineralization. Understanding the impact of cross-linked $\mathrm{BN}$ reinforced gelatin ESM on HOS cell ALP activity is important for bone tissue engineering. The ALP activity of cells cultured on gelatin and gelatin/BN ESM is measured and the results are shown in Figure 9a. No significant decrease in the ALP activity of cells cultured on 5GC ESM is observed in comparison to the control. These results prove that $\mathrm{BN}$ is biocompatible and does not affect ALP activity in HOS cells. 


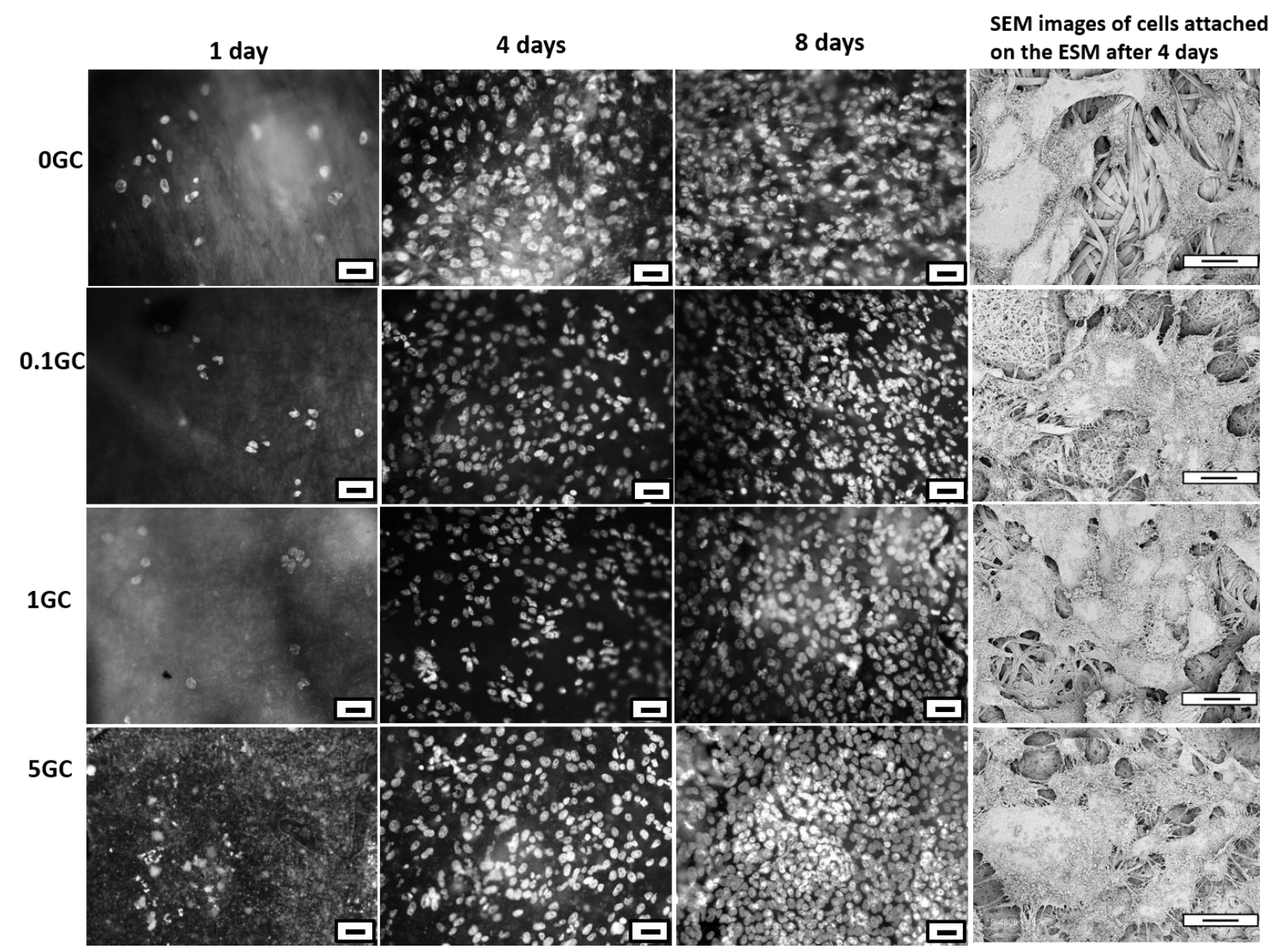

Figure 8. The fluorescent images of the Hoechst 33342 stained cells and SEM images of cells attached on the ESM. Scale bar indicates $30 \mu \mathrm{m}$

The effect of ESMs on cell viability are recorded and shown in the Figure 9b. Cells grown on tissue culture plate without material is considered as a control. Cell viability slightly decreases in the presence of the GC ESMs in comparison to control samples (1 day). However, BN concentration does not influence cell viability. These results suggest that the cross-linking affects cell viability and that boron nitride is biocompatible. Interestingly, by comparing 1, 4 and 8 days of culture, cell proliferation also increases with time in the presence of material thus strengthening the conclusion that $\mathrm{BN}$ is biocompatible. 

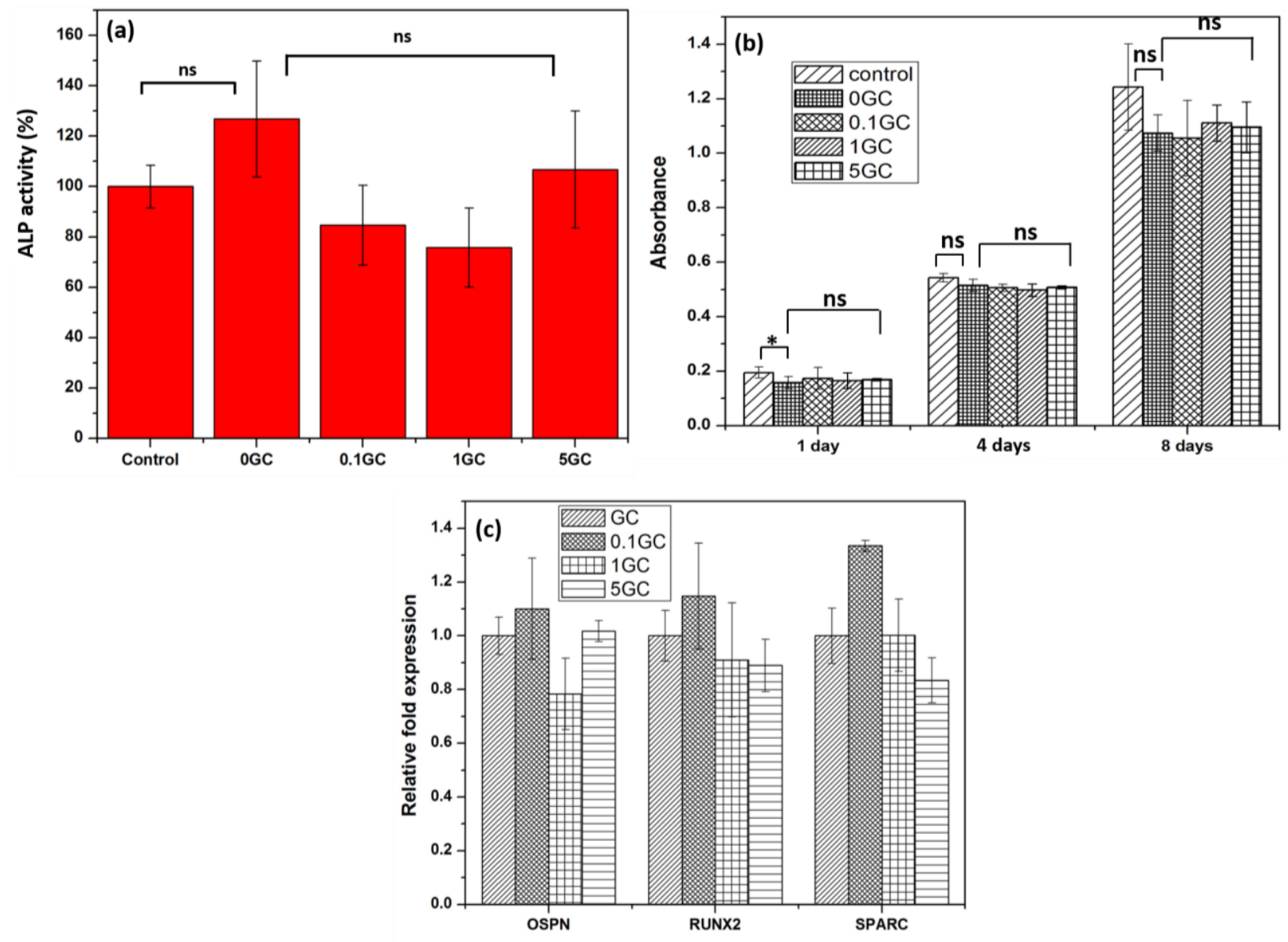

Figure 9. (a) Alkaline phosphatase activity, (b) cell viability and (c) quantification of osteoblast gene expression of cells grown on cross-linked ESM ( $\mathrm{ns}=$ no significance, $\mathrm{p}<0.05$ $=*, \mathrm{p}<0.005=* *)$.

Finally, the influence of BN concentration on osteoblast gene expression has been monitored by qPCR analysis (Figure 9c). Osteopontin (OSPN) gene expression is essential for bone mineralization. The presence of phosphorylation, negative charge from the aspartic acid and glutamic acid and calcium chelating sites in the OSPN protein facilitates bone mineralization. It is also proved that high degree of OSPN phosphorylation controls the calcium phosphate crystal growth ${ }^{66-67}$. The major role of RunX2 is to improve osteoblast differentiation and bone formation ${ }^{68}$. SPARC (Osteonectin) is a bone specific protein which plays important roles in linking bone mineral (calcium phosphate) with collagen ${ }^{69}$. Quantification of 
osteoblast-specific gene expression is a suitable approach to verify the osteogenic potential of HOS cells as previously used by others to monitor the "bone phenotype" of such cells ${ }^{32,70}$. The gene expression data are analyzed using Kruskal-Wallis ANOVA statistical test. The expression of OSPN and RunX2 is not significantly affected by the BN concentration $(p>0.05)$. SPARC expression increases in cells cultured on ESMs with highly exfoliated BN (0.1GC) in comparison to 0GC ( $p<0.05$ T-test), however $1 \mathrm{GC}$ and $5 \mathrm{GC}$ do not significantly affect SPARC expression in comparison to 0GC $(p>0.05(T$-test $))$. The exfoliated BN has no effect on osteoblast gene expression. However the mechanical properties are significantly improved by exfoliated $\mathrm{BN}$. The GO is found to be toxic at high concentration ${ }^{71}$. The influence of $\mathrm{BN}$ on osteoblast expression reported here evidences that $\mathrm{BN}$ is a biocompatible alternate to $\mathrm{GO}^{72}$. The ESM is highly biodegradable using the collagenase enzyme. On the basis of these results, it can thus be concluded that $\mathrm{BN}$ is biocompatible, biodegradable and represents a promising material for bone tissue engineering application.

\section{CONCLUSIONS}

$\mathrm{BN}$ reinforced gelatin ESMs are synthesized and characterized. The mechanical properties and stability under PBS are also investigated. DSC results show that gelatin structure displays only a small part of collagen-like triple helical structure meaning that fabrication of ESM with the presented method and using acetic acid as solvent favors coil structure formation. However, the exfoliated $\mathrm{BN}$ effectively reinforces the gelatin matrix and increases the Young's modulus. The cross-linked ESMs are highly stable in PBS and keep a fibrous morphology. The exfoliated BN/gelatin ESMs are highly bioactive since they form densely packed hydroxyapatite layers during mineralization in SBF. Cell viability assays, fluorescence imaging, osteoblast gene expression and ALP activity using HOS cells indicate that BN does 
not influence cell attachment or proliferation and that the $\mathrm{BN}$ reinforced gelatin ESMs are highly biocompatible and suitable for bone tissue engineering. The improved Young's modulus and mineralization of dense hydroxyapatite crystals clearly suggest that the exfoliated BN reinforces electrospun gelatin nanofibers. Regarding these results, BN reinforced gelatin ESMs are promising nontoxic, biocompatible materials for orthopedic applications.

\section{ACKNOWLEDGEMENTS}

S. N. acknowledges the financial support from Svaagata-Erasmus mundus program. The authors are thankful to Dr. Rajaram, Central Leather Research Institute (CLRI), Chennai, India and N. Masquelez, European Institute of Membranes, Montpellier, France, for valuable suggestions to DSC results. The human HOS osteosarcoma cell line is kindly donated by Dr. Maurel, Institute of Functional Genomics (IGF), Montpellier, France. The authors would like to acknowledge the "Institut Européen des Membranes (IEM)-UMR 5635" which supports this study through the health project PS1-2015-NewBone. The authors would like to thank the financial support from CEFIPRA (Project 5608-1), the Ligue Contre Le Cancer and the CNRS (Project “Osez l'Interdisciplinarité”).

\section{REFERENCES}

1. Djagny, K. B.; Wang, Z.; Xu, S., Gelatin: A Valuable Protein for Food and Pharmaceutical Industries: Review. Critical Reviews in Food Science and Nutrition 2001, 41 (6), 481-492.

2. Olsen, D.; Yang, C.; Bodo, M.; Chang, R.; Leigh, S.; Baez, J.; Carmichael, D.; Perälä, M.; Hämäläinen, E.-R.; Jarvinen, M.; Polarek, J., Recombinant collagen and gelatin for drug delivery. Advanced Drug Delivery Reviews 2003, 55 (12), 1547-1567. 
3. Li, R.-K.; Yau, T. M.; Weisel, R. D.; Mickle, D. A. G.; Sakai, T.; Choi, A.; Jia, Z.-Q., Construction of a Bioengineered Cardiac graft. The Journal of Thoracic and Cardiovascular Surgery 2000, 119 (2), 368-375.

4. $\quad$ Sakai, T.; Li, R.-K.; Weisel, R. D.; Mickle, D. A. G.; Kim, E. T. J.; Jia, Z.-Q.; Yau, T. M., The Fate of a Tissue-Engineered Cardiac Graft in the Right Ventricular Outflow Tract of the Rat. The Journal of Thoracic and Cardiovascular Surgery 2001, 121 (5), 932-942.

5. Sivakumar, M.; Panduranga Rao, K., Preparation, Characterization and In Vitro Release of Gentamicin from Coralline Hydroxyapatite-Gelatin Composite Microspheres. Biomaterials 2002, 23 (15), 3175-3181.

6. $\quad$ Ponticiello, M. S.; Schinagl, R. M.; Kadiyala, S.; Barry, F. P., Gelatin-Based Resorbable Sponge As a Carrier Matrix for Human Mesenchymal Stem Cells in Cartilage Regeneration Therapy. Journal of Biomedical Materials Research 2000, 52 (2), 246-255.

7. Tomihata, K.; Burczak, K.; Shiraki, K.; Yoshito, I., Cross-Linking and Biodegradation of Native and Denatured Collagen. Polymers of Biological and Biomedical Significance, American Chemical Society: 1993; Chapter 24, pp 275-286.

8. Nagarajan, S.; Soussan, L.; Bechelany, M.; Teyssier, C.; Cavailles, V.; PochatBohatier, C.; Miele, P.; Kalkura, N.; Janot, J.-M.; Balme, S., Novel Biocompatible Electrospun Gelatin Fiber Mats with Antibiotic Drug Delivery Properties. Journal of Materials Chemistry B 2016, 4 (6), 1134-1141.

9. Yaylaoğlu, M. B.; Korkusuz, P.; Örs, Ü.; Korkusuz, F.; Hasirci, V., Development of a Calcium Phosphate-Gelatin Composite as a Bone Substitute and its use in Drug Release. Biomaterials 1999, 20 (8), 711-719.

10. Lee, J.; Tae, G.; Kim, Y. H.; Park, I. S.; Kim, S.-H.; Kim, S. H., The Effect of Gelatin Incorporation into Electrospun poly(1-lactide-co- $\varepsilon$-caprolactone) fibers on Mechanical properties and Cytocompatibility. Biomaterials 2008, 29 (12), 1872-1879.

11. Zha, Z.; Teng, W.; Markle, V.; Dai, Z.; Wu, X., Fabrication of Gelatin Nanofibrous Scaffolds using Ethanol/Phosphate Buffer Saline as a Benign Solvent. Biopolymers 2012, 97 (12), 1026-1036.

12. Liu, X.; Smith, L. A.; Hu, J.; Ma, P. X., Biomimetic nanofibrous Gelatin/Apatite Composite Scaffolds for Bone Tissue engineering. Biomaterials 2009, 30 (12), 2252-2258.

13. Mistry, S.; Kundu, D.; Datta, S.; Basu, D., Comparison Of Bioactive Glass Coated And Hydroxyapatite Coated Titanium Dental Implants In The Human Jaw Bone. Australian Dental Journal 2011, 56 (1), 68-75.

14. Qu, T.; Liu, X., Nano-Structured Gelatin/Bioactive Glass Hybrid Scaffolds For The Enhancement Of Odontogenic Differentiation Of Human Dental Pulp Stem Cells. Journal of Materials Chemistry B 2013, 1 (37), 4764-4772.

15. Gupta, D.; Venugopal, J.; Mitra, S.; Giri Dev, V. R.; Ramakrishna, S., Nanostructured Biocomposite Substrates By Electrospinning And Electrospraying For The Mineralization Of Osteoblasts. Biomaterials 2009, 30 (11), 2085-2094.

16. Jang, J.-H.; Castano, O.; Kim, H.-W., Electrospun Materials As Potential Platforms For Bone Tissue Engineering. Advanced Drug Delivery Reviews 2009, 61 (12), 1065-1083.

17. Kim, H. W.; Song, J. H.; Kim, H. E., Nanofiber Generation Of GelatinHydroxyapatite Biomimetics For Guided Tissue Regeneration. Advanced Functional Materials 2005, 15 (12), 1988-1994.

18. Pease, R. S., An X-Ray Study Of Boron Nitride. Acta Crystallographica 1952, 5 (3), 356-361.

19. Lee, C.; Wei, X.; Kysar, J. W.; Hone, J., Measurement of the Elastic Properties and Intrinsic Strength of Monolayer Graphene. Science 2008, 321 (5887), 385-388.

20. Biscarat, J.; Bechelany, M.; Pochat-Bohatier, C.; Miele, P., Graphene-Like Bn/Gelatin Nanobiocomposites For Gas Barrier Applications. Nanoscale 2015, 7 (2), 613-618. 
21. Alem, N.; Erni, R.; Kisielowski, C.; Rossell, M. D.; Gannett, W.; Zettl, A., Atomically Thin Hexagonal Boron Nitride Probed By Ultrahigh-Resolution Transmission Electron Microscopy. Physical Review B 2009, 80 (15), 155425.

22. Jin, C.; Lin, F.; Suenaga, K.; Iijima, S., Fabrication of a Freestanding Boron Nitride Single Layer and Its Defect Assignments. Physical Review Letters 2009, 102 (19), 195505.

23. Chen, Z.-G.; Zou, J.; Liu, G.; Li, F.; Wang, Y.; Wang, L.; Yuan, X.-L.; Sekiguchi, T.; Cheng, H.-M.; Lu, G. Q., Novel Boron Nitride Hollow Nanoribbons. ACS Nano 2008, 2 (10), 2183-2191.

24. Corso, M.; Auwärter, W.; Muntwiler, M.; Tamai, A.; Greber, T.; Osterwalder, J., Boron Nitride Nanomesh. Science 2004, 303 (5655), 217-220.

25. Zhi, C.; Bando, Y.; Tang, C.; Kuwahara, H.; Golberg, D., Large-Scale Fabrication of Boron Nitride Nanosheets and Their Utilization in Polymeric Composites with Improved Thermal and Mechanical Properties. Advanced Materials 2009, 21 (28), 2889-2893.

26. Lin, Y.; Williams, T. V.; Connell, J. W., Soluble, Exfoliated Hexagonal Boron Nitride Nanosheets. The Journal of Physical Chemistry Letters 2009, 1 (1), 277-283.

27. Lin, Y.; Connell, J. W., Advances In 2d Boron Nitride Nanostructures: Nanosheets, Nanoribbons, Nanomeshes, And Hybrids With Graphene. Nanoscale 2012, 4 (22), 69086939.

28. Lu, T.; Wang, L.; Jiang, Y.; liu, Q.; Huang, C., Hexagonal Boron Nitride Nanoplates As Emerging Biological Nanovectors And Their Potential Applications In Biomedicine. Journal of Materials Chemistry B 2016, 4 (36), 6103-6110.

29. Menichetti, L.; De Marchi, D.; Calucci, L.; Ciofani, G.; Menciassi, A.; Forte, C., Boron Nitride Nanotubes For Boron Neutron Capture Therapy As Contrast Agents In Magnetic Resonance Imaging At 3 T. Applied Radiation and Isotopes 2011, 69 (12), 17251727.

30. Feng, S.; Zhang, H.; Yan, T.; Huang, D.; Zhi, C.; Nakanishi, H.; Gao, X.-D., FolateConjugated Boron Nitride Nanospheres For Targeted Delivery Of Anticancer Drugs. International Journal of Nanomedicine 2016, 11, 4573-4582.

31. Chen, X.; Wu, P.; Rousseas, M.; Okawa, D.; Gartner, Z.; Zettl, A.; Bertozzi, C. R., Boron Nitride Nanotubes Are Noncytotoxic and Can Be Functionalized for Interaction with Proteins and Cells. Journal of the American Chemical Society 2009, 131 (3), 890-891.

32. Lahiri, D.; Rouzaud, F.; Richard, T.; Keshri, A. K.; Bakshi, S. R.; Kos, L.; Agarwal, A., Boron Nitride Nanotube Reinforced Polylactide-Polycaprolactone Copolymer Composite: Mechanical Properties And Cytocompatibility With Osteoblasts And Macrophages In Vitro. Acta Biomaterialia 2010, 6 (9), 3524-3533.

33. Ciofani, G., L.Ricotti, S.Danti, S.Moscato, C.Nesti, D.Dalessandro, D.Dinucci, F.Chiellini, APietrabissa, M.petrini, A.Menciassi, Investigation Of Interactions Between Poly-L-Lysine-Coated Boron Nitride Nanotubes And C2c12 Cells: Up-Take, Cytocompatibility, And Differentiation. International Journal of Nanomedicine 2010, 5, 285. 34. Ciofani, G.; Raffa, V.; Menciassi, A.; Cuschieri, A., Folate Functionalized Boron Nitride Nanotubes and their Selective Uptake by Glioblastoma Multiforme Cells: Implications for their Use as Boron Carriers in Clinical Boron Neutron Capture Therapy. Nanoscale Research Letters 2008, 4 (2), 113 - 121.

35. Ferreira, T. H.; Rocca, A.; Marino, A.; Mattoli, V.; de Sousa, E. M. B.; Ciofani, G., Evaluation Of The Effects Of Boron Nitride Nanotubes Functionalized With Gum Arabic On The Differentiation Of Rat Mesenchymal Stem Cells. RSC Advances 2015, 5 (56), 4543145438.

36. Li, X.; Wang, X.; Jiang, X.; Yamaguchi, M.; Ito, A.; Bando, Y.; Golberg, D., Boron Nitride Nanotube-Enhanced Osteogenic Differentiation Of Mesenchymal Stem Cells. Journal of Biomedical Materials Research Part B: Applied Biomaterials 2016, 104 (2), 323-329. 
37. Zhi, C.; Bando, Y.; Tang, C.; Golberg, D., Immobilization of Proteins on Boron Nitride Nanotubes. Journal of the American Chemical Society 2005, 127 (49), 17144-17145. 38. Ciofani, G.; Genchi, G. G.; Liakos, I.; Athanassiou, A.; Dinucci, D.; Chiellini, F.; Mattoli, V., A Simple Approach To Covalent Functionalization Of Boron Nitride Nanotubes. Journal of Colloid and Interface Science 2012, 374 (1), 308-314.

39. Ciofani G, D. S.; Genchi, GG.; Alessandro, D.; Pellequer, JL.; Odorico, M.; Mattoli, V.; Giorgi, M., Pilot In VivoToxicological Investigation of Boron Nitride Nanotubes International Journal of Nanomedicine 2012, 7, 19-24.

40. Alessandra, Salvetti.; Leonardo Rossi, P.; Iacopetti, X. L., Simone; Nitti, T. P.; Virgilio Mattoli, D.; Golberg, G. C., In Vivo Biocompatibility Of Boron Nitride Nanotubes: Effects On Stem Cell Biology And Tissue Regeneration In Planarians. Nanomedicine 2015, 10 (12), 1911-1922.

41. Lahiri, D.; Singh, V.; Benaduce, A. P.; Seal, S.; Kos, L.; Agarwal, A., Boron Nitride Nanotube Reinforced Hydroxyapatite Composite: Mechanical And Tribological Performance And In-Vitro Biocompatibility To Osteoblasts. Journal of the Mechanical Behavior of Biomedical Materials 2011, 4 (1), 44-56.

42. Agarwal, S.; Wendorff, J. H.; Greiner, A., Use Of Electrospinning Technique For Biomedical Applications. Polymer 2008, 49 (26), 5603-5621.

43. Franceschi, R. T.; Iyer, B. S., Relationship Between Collagen Synthesis And Expression Of The Osteoblast Phenotype In Mc3t3-E1 Cells. Journal of Bone and Mineral Research 1992, 7 (2), 235-246.

44. Schindler, M.; Ahmed, I.; Kamal, J.; Nur-E-Kamal, A.; Grafe, T. H.; Young Chung, H.; Meiners, S., A Synthetic Nanofibrillar Matrix Promotes In Vivo-Like Organization And Morphogenesis For Cells In Culture. Biomaterials 2005, 26 (28), 5624-5631.

45. Yoshimoto, H.; Shin, Y. M.; Terai, H.; Vacanti, J. P., A Biodegradable Nanofiber Scaffold By Electrospinning And Its Potential For Bone Tissue Engineering. Biomaterials 2003, 24 (12), 2077-2082.

46. Michael Shin, H. Y., and Joseph P. Vacanti., In Vivo Bone Tissue Engineering Using Mesenchymal Stem Cells on a Novel Electrospun Nanofibrous Scaffold Tissue Engineering, Parts A, B, \& C 2004, 10 (1-2) 33-41.

47. Li, M.; Guo, Y.; Wei, Y.; MacDiarmid, A. G.; Lelkes, P. I., Electrospinning Polyaniline-Contained Gelatin Nanofibers For Tissue Engineering Applications. Biomaterials 2006, 27 (13), 2705-2715.

48. Chaaya, A. A.; Bechelany, M.; Balme, S.; Miele, P., ZnO 1D Nanostructures Designed By Combining Atomic Layer Deposition And Electrospinning For Uv Sensor Applications. Journal of Materials Chemistry A 2014, 2 (48), 20650-20658.

49. Achet, D.; He, X. W., Determination Of The Renaturation Level In Gelatin Films. Polymer 1995, 36 (4), 787-791.

50. $\quad$ Samouillan, V.; Delaunay, F.; Dandurand, J.; Merbahi, N.; Gardou, J.-P.; Yousfi, M.; Gandaglia, A.; Spina, M.; Lacabanne, C., The Use Of Thermal Techniques For The Characterization And Selection Of Natural Biomaterials. Journal of Functional Biomaterials 2011, 2 (3), 230-248.

51. Kokubo, T.; Kushitani, H.; Sakka, S.; Kitsugi, T.; Yamamuro, T., Solutions Able To Reproduce In Vivo Surface-Structure Changes In Bioactive Glass-Ceramic A-W3. Journal of Biomedical Materials Research 1990, 24 (6), 721-734.

52. Chang, M.; Ikoma, T.; Kikuchi, M.; Tanaka, J., Preparation Of A Porous Hydroxyapatite/Collagen Nanocomposite Using Glutaraldehyde As A Crosslinkage Agent. Journal of Materials Science Letters 2001, 20 (13), 1199-1201.

53. Yao, B.; Liu, L.; Su, W. H., Formation, Characterization, And Properties Of A New Boron-Carbon-Nitrogen Crystal. Journal of Applied Physics 1999, 86 (5), 2464-2467. 
54. Bigi, A.; Panzavolta, S.; Rubini, K., Relationship Between Triple-Helix Content And Mechanical Properties Of Gelatin Films. Biomaterials 2004, 25 (25), 5675-5680.

55. Ebrahimi, R., Influence Of Ultrasonic Parameters On Degradation Of Acrylic Acid/Acrylamide Copolymer Based Superabsorbent Hydrogels Cross-Linked With Nmba. Iranian Polymer Journal 2012, 21 (1), 11-20.

56. Siimon, K.; Siimon, H.; Järvekülg, M., Mechanical Characterization Of Electrospun Gelatin Scaffolds Cross-Linked By Glucose. Journal of Materials Science: Materials in Medicine 2015, 26 (1), 1-9.

57. Zhang, Y. Z.; Venugopal, J.; Huang, Z. M.; Lim, C. T.; Ramakrishna, S., Crosslinking Of The Electrospun Gelatin Nanofibers. Polymer 2006, 47 (8), 2911-2917.

58. Lee, J. B.; Kim, S. E.; Heo, D. N.; Kwon, I. K.; Choi, B.-J., In Vitro Characterization Of Nanofibrous Plga/Gelatin/Hydroxyapatite Composite For Bone Tissue Engineering. Macromolecular Research 2010, 18 (12), 1195-1202.

59. Wang, Y.; Zhang, W.; Yuan, J.; Shen, J., Differences In Cytocompatibility Between Collagen, Gelatin And Keratin. Materials Science and Engineering: C 2016, 59, 30-34.

60. Hwang, P. T. J.; Murdock, K.; Alexander, G. C.; Salaam, A. D.; Ng, J. I.; Lim, D.-J.; Dean, D.; Jun, H.-W., Poly(E-Caprolactone)/Gelatin Composite Electrospun Scaffolds With Porous Crater-Like Structures For Tissue Engineering. Journal of Biomedical Materials Research Part A 2016, 104 (4), 1017-1029.

61. Forsgren, J.; Svahn, F.; Jarmar, T.; Engqvist, H., Formation And Adhesion Of Biomimetic Hydroxyapatite Deposited On Titanium Substrates. Acta Biomaterialia 2007, 3 (6), 980-984.

62. Diallo-Garcia, S.; Osman, M. B.; Krafft, J.-M.; Casale, S.; Thomas, C.; Kubo, J.; Costentin, G., Identification Of Surface Basic Sites And Acid-Base Pairs Of Hydroxyapatite. The Journal of Physical Chemistry C 2014, 118 (24), 12744-12757.

63. Martinez, A. W.; Caves, J. M.; Ravi, S.; Li, W.; Chaikof, E. L., Effects Of Crosslinking On The Mechanical Properties, Drug Release And Cytocompatibility Of Protein Polymers. Acta Biomaterialia 2014, 10 (1), 26-33.

64. Ikeda T1, F. Y., Tsuchida N., In Vitro Differentiation Of The Human Osteosarcoma Cell Lines, Hos And Khos. Virchows Arch B Cell Pathol Incl Mol Pathol 1992, 3 (62) 199206.

65. Cai, B.; Rao, L.; Ji, X.; Bu, L.-L.; He, Z.; Wan, D.; Yang, Y.; Liu, W.; Guo, S.; Zhao, X.-Z., Autofluorescent Gelatin Nanoparticles As Imaging Probes To Monitor Matrix Metalloproteinase Metabolism Of Cancer Cells. Journal of Biomedical Materials Research Part A 2016, 104 (11), 2854-2860.

66. Zurick, K. M.; Qin, C.; Bernards, M. T., Mineralization Induction Effects Of Osteopontin, Bone Sialoprotein, And Dentin Phosphoprotein On A Biomimetic Collagen Substrate. Journal of Biomedical Materials Research Part A 2013, 101A (6), 1571-1581. 67. Yuan, Q.; Jiang, Y.; Zhao, X.; Sato, T.; Densmore, M.; Schüler, C.; Erben, R. G.; McKee, M. D.; Lanske, B., Increased Osteopontin Contributes To Inhibition Of Bone Mineralization In Fgf23-Deficient Mice. Journal of Bone and Mineral Research 2014, 29 (3), 693-704.

68. Franceschi, R. T.; Xiao, G., Regulation Of The Osteoblast-Specific Transcription Factor, Runx2: Responsiveness To Multiple Signal Transduction Pathways. Journal of Cellular Biochemistry 2003, 88 (3), 446-454.

69. Termine, J. D.; Kleinman, H. K.; Whitson, S. W.; Conn, K. M.; McGarvey, M. L.; Martin, G. R., Osteonectin, A Bone-Specific Protein Linking Mineral To Collagen. Cell 1981, $26(1), 99-105$. 
70. Kim, M.-C.; Hong, M.-H.; Lee, B.-H.; Choi, H.-J.; Ko, Y.-M.; Lee, Y.-K., Bone Tissue Engineering By Using Calcium Phosphate Glass Scaffolds And The Avidin-Biotin Binding System. Annals of Biomedical Engineering 2015, 43 (12), 3004-3014.

71. Guo, X.; Mei, N., Assessment Of The Toxic Potential Of Graphene Family Nanomaterials. Journal of Food and Drug Analysis 2014, 22 (1), 105-115.

72. Liu, Y.; Luo, Y.; Wu, J.; Wang, Y.; Yang, X.; Yang, R.; Wang, B.; Yang, J.; Zhang, N., Graphene Oxide Can Induce In Vitro And In Vivo Mutagenesis. Scientific Reports 2013, 3,3469 . 


\section{TABLE OF CONTENTS GRAPHIC}

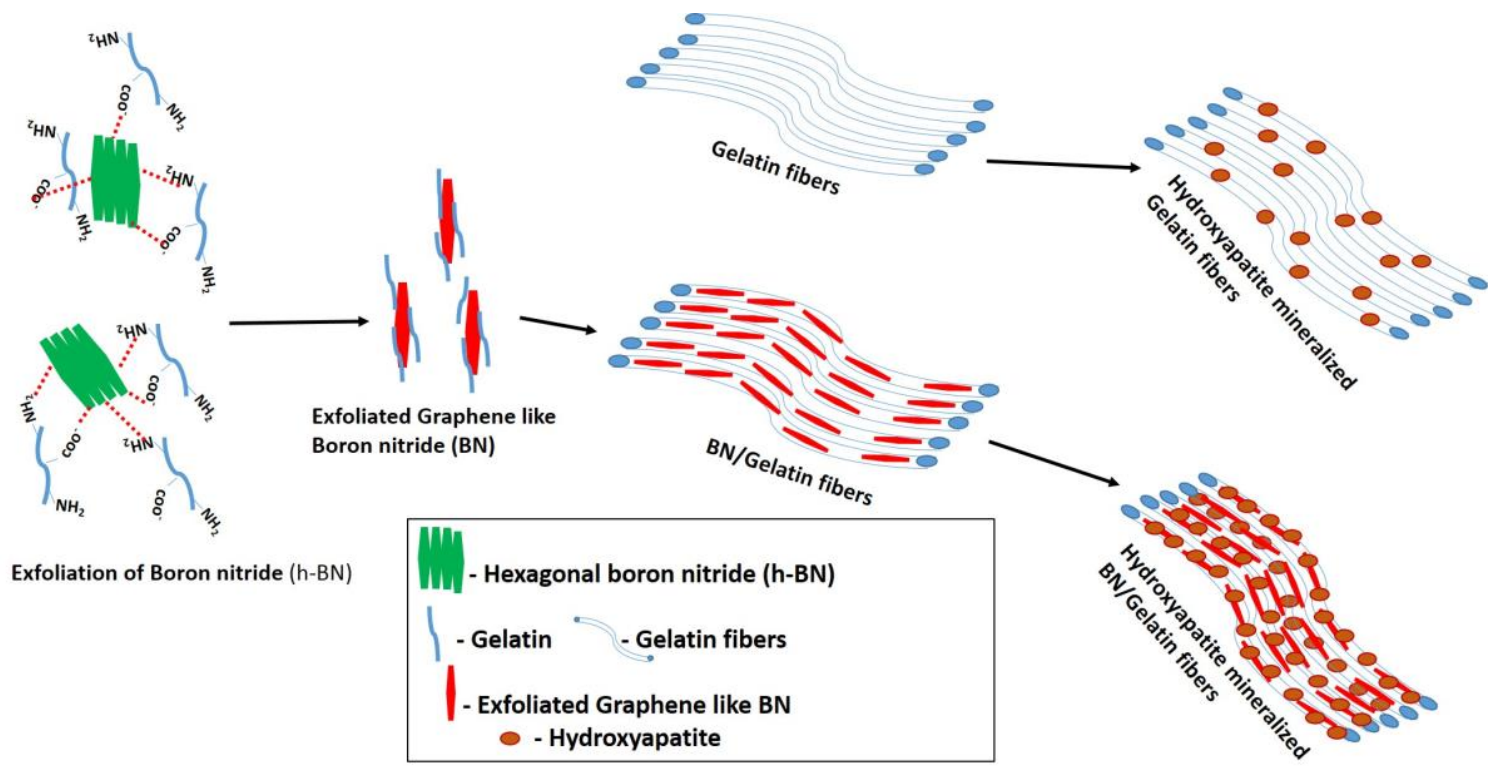

